\title{
Simvastatin Therapy Attenuates Memory Deficits that Associate to Brain Monocyte Infiltration in Chronic Hypercholesterolemic ApoE ${ }^{-/-}$Mice
}

Short running title: Monocytes and memory deficits in hypercholesterolemia.

Nicholas Don-Doncow $^{\mathrm{a}, \mathrm{b}}$, Frank Matthes ${ }^{\mathrm{a}, \mathrm{b}}$, Hana Matuskova ${ }^{\mathrm{a}, \mathrm{b}, \mathrm{c}, \mathrm{d}}$, Sara Rattik ${ }^{\mathrm{e}}$, Lotte Vanherle ${ }^{\mathrm{a}, \mathrm{b}}$, Sine Kragh Petersen $^{\mathrm{f}}$, Anetta Härtlova ${ }^{\mathrm{f}} \&$ Anja Meissner ${ }^{\mathrm{a}, \mathrm{b}, \mathrm{d}}$

${ }^{a}$ Department of Experimental Medical Sciences, Lund University, Sweden

${ }^{\mathrm{b}}$ Wallenberg Centre for Molecular Medicine, Lund University, Sweden

${ }^{\mathrm{c}}$ Department of Neurology, University Hospital Bonn, Germany

${ }^{\mathrm{d}}$ German Center for Neurodegenerative Diseases, Bonn, Germany

${ }^{\mathrm{e}}$ Department of Clinical Science, Lund University, Sweden

${ }_{\mathrm{f}}^{\mathrm{f}}$ Department of Microbiology and Immunology, Wallenberg Centre for Molecular and Translational Medicine, University of Gothenburg, Sweden

Correspondence to: Anja Meissner; Klinikgatan 32, SE-22184 Lund, Sweden; anja.meissner@med.lu.se; +46 (0)4622 20641

\section{Manuscript category: Original Article}

\section{Word count: 4729}

Acknowledgement: The authors thank Dr. Anna Planas for contributing aged $\mathrm{ApoE}^{-/-}$mice and allowing us to use her behavioral platform, Francisca Ruiz for help with the treatment of the $\mathrm{ApoE}^{-/}$mice and the support with Elisa experiments, Dr. Harry Björkbacka for providing aged $\mathrm{ApoE}^{-/}$mice and access to his flow cytometer, and Yun Zhang for help with running some of the flow cytometry.

Conflict of Interest: None declared.

\begin{abstract}
Background and Purpose: Metabolic and cardiovascular disease is the most prevalent disease burden in the world and risk factor for progressive cognitive decline. Evidence associates cardiovascular risk factors to unfavorable systemic and neuro-inflammation and to cognitive decline. Cardiovascular therapeutics (e.g., statins and antihypertensives) possess immune-modulatory functions in parallel to their cholesterol- or blood pressure (BP)lowering properties. How their ability to modify immune responses affects cognitive function is unknown.

Experimental Approach: By using flow cytometry, Elisa, qPCR, Western blotting and object recognition tasks, we examined the effect of chronic hypercholesterolemia on inflammation and memory function in Apolipoprotein E (ApoE) knockout mice and normocholesterolemic wild-type mice.

Key results: Chronic hypercholesterolemia associated to moderate BP elevations and apparent immune system activation characterized by increases in circulating pro-inflammatory Ly6Chi monocytes in ApoE ${ }^{-/-}$mice. The persistent low-grade immune activation associated to chronic hypercholesterolemia facilitates the infiltration of pro-inflammatory Ly6Chi monocytes into the brain of aged $\mathrm{ApoE}^{-/-}$but not wild-type mice, linking to memory dysfunction. Therapeutic administration of cholesterol-lowering simvastatin reduced BP, systemic and neuro-
\end{abstract}


inflammation, and the occurrence of memory deficits in aged $\mathrm{ApoE}^{-/}$mice. BP-lowering therapy alone (i.e. hydralazine) attenuated some neuro-inflammatory signatures but not the occurrence of memory deficits. When administered in combination, it reduced effectiveness of statin therapy in some instances.

Conclusions and Implications: Our study suggests a link between chronic hypercholesterolemia, myeloid cell activation and neuro-inflammation with memory impairment. Cholesterol-lowering therapy provides effectiveness to attenuate memory impairment and inflammatory events and hence, emerges as safe therapeutic strategy to control hypercholesterolemia-associated memory decline.

Keywords: chronic hypercholesterolemia, immune activation, pro-inflammatory monocytes, neuroinflammation, memory impairment, statin therapy

\section{What is already known:}

- cardiovascular risk factors link to unfavorable systemic and neuro-inflammation and to cognitive decline

- cardiovascular therapeutics possess immune-modulatory functions in parallel to their principle cholesterol- or blood pressure-lowering properties

\section{What this study adds:}

- links chronic hypercholesterolemia in mice to specific immune responses and the development of memory impairment

- favorable outcomes in respect to neuro-inflammation and memory function in hypercholesterolemic mice after statin therapy

\section{Clinical significance:}

- opens the door for available CVD therapeutics with long-term safety profiles to managing cognitive dysfunction

- targeted monitoring of inflammatory signature in patients with high cardiovascular burden (surrogate biomarker of cognitive decline)

\section{Introduction:}

Cognitive decline is an increasingly common problem that progresses with age. By gradually interfering with daily functioning and well-being, it poses an enormous burden on affected people and their environment (Meissner, 2016; Wimo et al., 2011). In recent years, the apparent role of cardiovascular risk factors as important modifiable elements in the development of cognitive decline has become subject of clinical as well as pre-clinical research efforts (Gasecki, Kwarciany, Nyka, \& Narkiewicz, 2013; Meissner, 2016; Meissner, Minnerup, Soria, \& Planas, 2016). A prominent link between mid-life chronic hypercholesterolemia and/or hypertension and the development of dementia later in life exists (Moreira et al., 2012; van Vliet, 2012). As a consequence, the management of cardiovascular risk factors not only serves to preventing often detrimental acute consequences of for instance, hypertension or dyslipidemia but also to minimize potential adverse cognitive outcomes later on. A number of observational and randomized studies reported beneficial effects of antihypertensive therapies on cognitive outcome (Hajjar et al., 2012; Peters et al., 2008; Rigaud, Olde-Rikkert, Hanon, Seux, \& Forette, 2002). Nonetheless, existing distinctions regarding effectiveness between different classes of hypertension medication have been shown (Hajjar et al., 2012). Likewise, the use of statins in controlling risk factors for dementia prevention or treatment is controversially discussed. Their therapeutic efficacy that initially emerged from 
findings showing its positive effects on various factors related to memory function (Jick, Zornberg, Jick, Seshadri, \& Drachman, 2000; Rockwood et al., 2002) was increasingly argued as case studies raised concerns regarding a contributory role of statins in development of cognitive problems (Suraweera, de Silva, \& Hanwella, 2016; Wagstaff, Mitton, Arvik, \& Doraiswamy, 2003). Due to the discrepancies observed between studies and the lack of knowledge regarding underlying mechanisms, strategies to combat cognitive impairment resulting from cardiovascular risk factors or cardiovascular disease (CVD) are yet to be established.

Immune system alterations and inflammation are not only hallmarks of many CVDs and their risk factors but have increasingly been recognized as contributors to impaired cognitive function in older people (McRae, Dahlstrom, Polinsky, \& Ling, 1993; Pietschmann et al., 2003; Tan \& Seshadri, 2010). Pharmaceuticals directed against inflammation evidently improve cognitive alterations associated to normal aging, CVDs, and classical neurodegenerative diseases (Don-Doncow, Vanherle, Zhang, \& Meissner, 2019; Meissner et al., 2015). Multiple drugs commonly used in the cardiovascular field possess immune-modulatory actions in parallel to their principle cholesterol- or blood pressure (BP)-lowering effects (Alaarg et al., 2016; Sparrow et al., 2001). One of the bottlenecks hampering the targeted use of CVD therapeutics as approach to minimize CVD-associated cognitive impairment is the lacking understanding of specific inflammatory signatures that relate to cognitive impairment in patients with increased cardiovascular burden.

The herein presented study investigated the effect of chronic exposure to elevated plasma cholesterol levels on systemic and neuro-inflammation and memory function in ageing mice. Using mice deficient in Apolipoprotein E (ApoE), which normally facilitates cholesterol clearance in the liver and thus, controls plasma cholesterol levels, allowed us to mimic a chronically hypercholesterolemic state under normal dietary conditions. To study the effect of chronic hypercholesterolemia on systemic and neuro-inflammation and memory performance, we compared ApoE ${ }^{-1-}$ mice to normocholesterolemic WT mice. We tested the efficacy of CVD therapeutics as treatment for memory impairment associated to the increased cardiovascular burden in aged $\mathrm{ApoE}^{-/-}$mice. To this end, we therapeutically administered the statin simvastatin that has been attributed a strong anti-inflammatory character by regulating proliferation and activation of macrophages (Mullen, Ferdjani, \& Sacre, 2015; Rezaie-Majd et al., 2002), and/or the smooth muscle relaxant agent hydralazine, known to reduce leukocyte migration in spontaneously hypertensive rats (Rodrigues et al., 2008). Our findings provide evidence that early life exposure to high cholesterol rather than increases in plasma cholesterol and BP later in life negatively affect memory performance. We underscore a role of myeloid cell activation in the development of neuro-inflammation associated to chronic hypercholesterolemia as well as cell type-specific drug effects that may limit their efficacy.

\section{Material and Methods:}

An expanded Methods section is available in the online Data Supplement.

Materials: All chemical reagents and solutions were purchased from Fisher Scientific (Göteborg, Sweden), Saveen \& Werner (Limhamn, Sweden) or Sigma-Aldrich (Stockholm, Sweden) unless otherwise stated. Commercially available primary antibodies against CD3 (Bio-techne, UK), PSD-95, SNAP-25, NeuN and BDNF (Abcam, UK), CD68 (Invitrogen, Sweden) and Iba-1 (Wako, Japan) were used for immunofluorescence. Secondary antibodies Alexa Fluor 488 donkey anti-mouse, anti-rabbit, goat anti-rabbit or goat anti-rat Fluor 594 (Nordic Biosite, Sweden) were used for visualization. Primers for qPCR were purchased from Eurofins (Ebersberg, Germany).

Animals: This investigation conforms to the Guide for Care and Use of Laboratory Animals published by the European Union (Directive 2010/63/EU) and with the ARRIVE guidelines. All animal care and experimental protocols were approved by the institutional animal ethics committees at the University of Barcelona (CEEA) and Lund University (5.8.18-12657/2017) and conducted in accordance with European animal protection laws. Male wild-type (WT) C57Bl/6J mice and Apolipoprotein E knockout (ApoE ${ }^{-/}$) mice (B6.129P2-Apoe $(\mathrm{tm} 1 \mathrm{Unc}) / \mathrm{J})$ were obtained from Jackson Laboratories and bred in a conventional animal facility under standard 
conditions with a $12 \mathrm{~h}: 12 \mathrm{~h}$ light-dark cycle, and access to food (standard rodent diet) and water ad libitum. Mice with a body weight $\mathrm{BW} \geq 25 \mathrm{~g}$ were housed in groups of 4-5 in conventional transparent polycarbonate cages with filter tops. ApoE ${ }^{-/}$and $\mathrm{C} 57 \mathrm{Bl} / 6 \mathrm{~J}$ (WT) mice at the age of 4 and 12 months ( $\mathrm{N}=10$ per group) were used to assess the effect of ageing on inflammatory status and brain phenotype (Fig.1A). At the age of 12 months, another group of $\mathrm{ApoE}^{-/-}$mice was randomly assigned to the following experimental groups using the computer software Research Randomizer (http://www.randomizer.org/): aged control, aged + hydralazine $(25 \mathrm{mg} / \mathrm{L})$, aged + simvastatin $(2.5 \mathrm{mg} / \mathrm{L})$, and aged + hydralazine/simvastatin combination $(\mathrm{N}=10$ for simvastatin and hydralazine treatment; $\mathrm{N}=8$ for combination treatment). The calculated doses given to the mice were $5 \mathrm{mg} / \mathrm{kg} / \mathrm{d}$ for hydralazine and $0.5 \mathrm{mg} / \mathrm{kg} / \mathrm{d}$ for simvastatin, which corresponds to $10 \mathrm{mg} / \mathrm{kg} / \mathrm{d}$ and $20 \mathrm{mg} / \mathrm{kg} / \mathrm{d}$ in humans, respectively (allometric scaling was used to convert doses amongst species (Nair \& Jacob, 2016)). Treatment was administered via drinking water over a course of two months. The mice in this experimental cohort were 14 months of age at time of sacrifice (Fig.1B). Apo ${ }^{-/-}$mice at the age of 4 months were used as young controls $(\mathrm{N}=10)$. To ensure blinding experiments were performed after the animals and samples had received codes that did not reveal the identity of the treatment. In order to obey the rules for animal welfare, we designed experimental groups in a way that minimizes stress for the animals and guarantees maximal information using the lowest group size possible when calculated with a type I error rate of $\alpha=0.05(5 \%)$ and Power of $1-\beta>0.8(80 \%)$ based on preliminary experiments. At termination, brain tissue was distributed to the different experiments as follows: Young (4 months) and aged (12 months) WT and $\mathrm{ApoE}^{-/-}$mice ( $\mathrm{N}=10$ each) for flow cytometric assessment of one hemisphere, $\mathrm{N}=5$ each for cortex and hippocampus fractionation of one hemisphere and $\mathrm{N}=5$ for whole hemisphere RNA and protein isolation (Fig.1A). Young (4 months), aged (14 months), hydralazine- and simvastatin treated $\left(\mathrm{N}=5\right.$ each) and combination-treated $(\mathrm{N}=3) \mathrm{ApoE}^{-/-}$mice for whole brain cryo-sectioning, cortex and hippocampus fractionation of one hemisphere $(\mathrm{N}=5$ each) as well as one hemisphere $(\mathrm{N}=5$ each) for whole hemisphere RNA and protein isolation (Fig.1B).

Open Field testing: To test novel environment exploration, general locomotor activity, and screen for anxietyrelated behavior mice were subjected to an open field exploration task using a video tracking system and the computer software EthoVision XT® (Noldus Information Technology, Netherlands) as described before.(Meissner et al., 2015) Mice were placed individually into an arena $(56 \times 56 \mathrm{~cm})$, which was divided into a grid of equally sized areas. The software recorded each line crossing as one unit of exploratory activity. The following behavioral parameters were measured: activity, active time, mobile time, slow activity, mobile counts, and slow mobile counts.

Novel object recognition (NOR): As previously described,(Lidington et al., 2019; Meissner et al., 2016; Meissner et al., 2015) a NOR task was employed to assess non-spatial memory components. Briefly, mice were habituated to the testing arena for 10 minutes over a period of 3 days. On test day, each mouse was exposed to two objects for 10 minutes. $5 \mathrm{~min}$ or $24 \mathrm{hrs}$ later, mice were re-exposed to one object from the original test pair and to a novel object. The movements of the animal were video tracked with the computer software EthoVision XT® (Noldus Information Technology, Netherlands). A delay interval of 5 minutes was chosen to test short-term retention of object familiarity, and with a delay interval longer of $24 \mathrm{hrs,} \mathrm{we} \mathrm{tested} \mathrm{long-term} \mathrm{hippocampus-dependent}$ memory function.(Baker \& Kim, 2002; Meissner et al., 2016) A recognition index (RI) as the main index of retention was calculated by the time spent investigating the novel object relative to the total object investigation $\left[\mathrm{RI}=T_{\text {Novel }} /\left(T_{\text {Novel }}+T_{\text {Familiar }}\right)\right]$. RI $=0.5$ indicates no preference for neither familiar nor novel object. Mice with total object exploration times ( $\left.T_{\text {Novel }}+T_{\text {Familiar }}\right)$ below $20 \mathrm{~s}$ were excluded from the analysis.

Object placement task: To test spatial recognition memory, mice were placed individually into an arena $(56 \times$ $56 \mathrm{~cm}$ ). Each mouse was exposed to two objects for 10 minutes. 5 min later, mice were re-exposed to both objects, of which one remained in the original place and the second object was moved to a novel place. Exploration of the objects was assessed manually with a stopwatch when mice sniffed, whisked, or looked at the objects from no more than $1 \mathrm{~cm}$ away. The time spent exploring the objects in new (novel) and old (familiar) locations was recorded during $5 \mathrm{~min}$. A location index was calculated $\mathrm{RI}=T_{\text {Novel }} /\left(T_{\text {Novel }}+T_{\text {Familiar }}\right)$, where $T_{\text {novel }}$ is the time spent exploring the displaced object and $\mathrm{T}_{\text {familiar }}$ is the time spent exploring the non-displaced object. $\mathrm{RI}=0.5$ indicates 
no preference for neither familiar nor novel object. Mice with total object exploration times $\left(T_{\text {Novel }}+T_{\text {Familiar }}\right)$ below 20s were excluded from the analysis.

Blood pressure measurements: BP was measured in conscious mice using tail-cuff plethysmography (Kent Scientific, CODA, UK). After a one-week handling period, mice were acclimatized to the restrainers and the tail cuff for a training period of 7 days. Mice were trained to walk into the restrainers and the holders were adjusted to limit the amount of movement. During this training period, first BP measurement were performed to familiarize the animals with the experimental procedure (e.g., cuff inflation). BP measurements were conducted in a designated quiet area where the mice were protected from direct light. Before and during each measurement, mice are placed on a heating pad kept at $35^{\circ} \mathrm{C}$. Actual BP measurements commenced after the training week. Data were recorded once mice presented with stable readings over the course of one week. During BP measurements, 30 inflation cycles were recorded of which the first 14 were regarded as acclimatization cycles and only cycles 15-30 were included in the analyses. BP was assessed at the age of 4 and 12 months in $\mathrm{ApoE}^{-/-}$ and WT mice (Fig.1A). In aged $\mathrm{ApoE}^{-/-}$mice that received treatment, BP was longitudinally assessed at experiment start (12 months) and after 8 weeks of treatment (14 months; Fig.1B).

Fluorescence activated cell sorting: Before euthanasia through cervical dislocation, mice were sedated using inhalation anesthesia (isofluorane $2.5 \%$ at $1.5 \mathrm{~L} / \mathrm{min}$ in room air) for whole blood collection. Whole blood was collected in EDTA-coated tubes and red blood cells were lysed before samples were incubated in $\mathrm{F}_{\mathrm{c}}$ block solution; FACS buffer (PBS + 2 \% FBS + 2 mM EDTA; pH 7.4) + anti-CD16/CD32, for 15 minutes followed by primary antibodies for 30 minutes at $4^{\circ} \mathrm{C}$. After centrifugation, the supernatant was decanted, washed, and pellets were re-suspended in FACS buffer. Brain tissue was enzymatically digested and homogenized. After density separation using Percoll (GE Healthcare), pellets were reconstituted in $\mathrm{F}_{\mathrm{c}}$ block and incubated for 15 minutes prior to staining with antibodies for $30 \mathrm{~min}$ (see data supplement for detailed list of antibodies). Data acquisition was carried out in a BD LSR Fortessa cytometer using FacsDiva software Vision 8.0 (BD Biosciences). Data analysis was performed with FlowJo software (version 10, TreeStar Inc., USA). Cells were plotted on forward versus side scatter and single cells were gated on FSC-A versus FSC-H linearity.

Brain macrophage analysis: Coronal brain sections (10 $\mu$ m thickness) of each experimental group were immunestained with Iba1 (WAKO, Japan) and CD68 (Invitrogen, Sweden). The total number of Iba1+ cells was counted in two regions of the hippocampus (dentate gyrus; DG and the cornu ammonis 1; CA1) in each hemisphere and in five regions of interests (ROIs) of the cortex using a fluorescence microscope (Axio Imager .M2, Zeiss). The cells were classified into three activation state groups based on morphology where Ramified (resting state) denotes Iba-1+ cells with a small cell body and extensive branched processes, Intermediate denotes Iba-1+ cells with enlarged cell body and thickened, reduced branches not longer than twice the cell body length and Round (active state) denotes Iba- $1+$ cells with round cell body without visible branches. In all sections, the total numbers of CD68+ Iba1+ cells were recorded.

Cell culture: Bone-marrow-derived macrophages (BMDMs) were generated by culturing freshly isolated mouse bone marrow cells from C57BL/6J mice in IMDM medium (GIBCO, Life Technologies) supplemented with 10\% FCS (GIBCO, Life Technologies), $100 \mathrm{U} / \mathrm{ml}$ penicillin (Sigma-Aldrich), and $100 \mathrm{U} / \mathrm{ml}$ streptomycin (SigmaAldrich), $2 \mathrm{mM}$ glutamine (Sigma-Aldrich) and 20\% (v/v) L929 conditional medium for 7 days. Human monocytic THP-1 cells (ATCC \#TIB-202) were cultured in RPMI-1640 containing 10\% fetal bovine serum, 0.05 $\mathrm{mM} \beta$-mercaptoethanol, and $1 \%$ penicillin-streptomycin in large culture flasks. Cell cultures were maintained at $37^{\circ} \mathrm{C}$ with $5 \% \mathrm{CO}_{2}$ and split $1: 4$ at a seeding density of $10^{6}$ cells. For differentiation, THP-1 cells were seeded in 6-well plates at a density of $3 \times 10^{5}$ cells and treated with $2.5 \mathrm{ng} / \mathrm{ml}$ phorbol-12-myristate-13-acetate (PMA) for $48 \mathrm{hrs}$. Prior to lipopolysaccharide (LPS) activation and treatment, cells were allowed to rest in culture media for 24 hrs. Human peripheral blood mononuclear cells (PBMCs) were isolated using Ficoll-Paque Plus (GE healthcare) density gradient centrifugation from donated blood of healthy volunteers. After centrifugation, the PBMC layers were isolated and washed with PBS to remove erythrocytes and granulocytes. PBMCs purification was performed using anti-human CD14 magnetic beads (Miltenyi Biotec) according to the manufacturer's 
instructions. Monocytes were maintained in RPMI 1640 (Gibco, Thermo Scientific) with $10 \%$ FCS (Gibco, Thermo Scientific), $2 \mathrm{mM}$ glutamine (Gibco, Thermo Scientific), $100 \mathrm{U} / \mathrm{mL}$ penicillin and $100 \mu \mathrm{g} / \mathrm{mL}$ streptomycin (Gibco, Thermo Scientific). For macrophage differentiation and maturation, human monocytes were plated onto tissue culture-treated 24 -well plates at a density of $3 \times 10^{5}$ cells/well. The medium was supplemented with $100 \mathrm{ng} / \mathrm{mL}$ recombinant human M-CSF using CellXVivo ${ }^{\mathrm{TM}}$ kit (R\&D Systems) and differentiated for 5-7 days prior to use.

Cells were incubated with $1 \mu \mathrm{g} / \mathrm{ml}$ LPS (Invitrogen, Sweden) for $6 \mathrm{hrs}$ prior to a $12 \mathrm{hrs}$ treatment with $1 \mu \mathrm{M}$ simvastatin (Bio-techne, UK), $10 \mu \mathrm{M}$ hydralazine (Sigma-Aldrich) and/or a combination of both. The concentrations were chosen based on the dosing regimen administered in the in vivo studies. After incubation, cells were detached using cold PBS containing EDTA $(5 \mathrm{mM})$ and either stained for flow cytometry or centrifuged and processed for RNA and protein isolation using the Trizol method.

Western Blotting, qPCR, ELISA and histological experiments: Standard biochemical procedures were utilized for experiments involving reverse transcription polymerase chain reaction, quantitative PCR, Western blotting and histological experiments. Methodological details are provided in the data supplement.

Statistical analysis: All data are expressed as mean \pm SEM, where $\mathrm{N}$ is the number of animals or independent cell experiments. For comparisons of young and aged WT and $\mathrm{ApoE}^{-/-}$mice, two-way ANOVA with Sidak post hoc testing was used to assess the effects of genotype and age. For comparison of multiple independent groups, the parametric one-way ANOVA test was used, followed by Tukey's post hoc testing with exact $\mathrm{P}$ value computation. In case of non-normally distributed data (tested with Shapiro-Wilk test), the non-parametric Kruskal Wallis test with Dunn's post hoc testing and exact $\mathrm{P}$ value computation was used for multiple comparisons. For comparison of two groups a two-tailed unpaired t-test was utilized. Differences were considered significant at error probabilities of $\mathrm{P} \leq 0.05$. All statistical analyses were performed in GraphPad Version 8.1.2 (GraphPad Software, Inc).

\section{Results}

1. Chronic hypercholesterolemia contributes to the development of memory impairment: To investigate whether chronic exposure to higher-than-normal plasma cholesterol levels affects important brain functions (i.e. cognition) during ageing, we tested memory function in normocholesterolemic WT and hypercholesterolemia $\mathrm{ApoE}^{-/-}$mice at different ages (Fig.1A). In accordance with the increased cardiovascular burden in $\mathrm{ApoE}^{-/-}$ compared to WT mice (Table 1), long-term (hippocampus-dependent) memory function deteriorated with age in $\mathrm{ApoE}^{-/-}$mice, resulting in significantly lower recognition indices (RI) compared to age-matched WT controls $\left(\mathrm{RI} \leq 0.5\right.$; Fig.2A). Although neither aged WT nor aged $\mathrm{ApoE}^{-/-}$mice presented with signs of short-term (rhinocortical) memory impairment when compared to their young controls (Table S1), spatial short-term memory was compromised in aged $\mathrm{ApoE}^{-/}$mice as evident by a lower RI obtained in an object placement test $(\mathrm{RI} \leq 0.5$; Fig.2B). When testing for age-related changes in pre- and post-synaptic proteins in whole brain lysates of $\mathrm{ApoE}^{-/-}$mice, no differences in expression of synaptosomal associated protein (SNAP-25) or postsynaptic density protein 95 (PSD-95) were observed (Fig.2C). In accordance with previous studies (Masliah et al., 1995), however, ageing affected hippocampal but not cortical PSD-95 mRNA expression in $\mathrm{ApoE}^{-/-}$mice (Fig.2D). Taken together, these data imply brain region-specific negative effects of early and chronic hypercholesterolemia on memory function later in life.

2. Pro-inflammatory monocytes infiltrate the brain of aged ApoE ${ }^{-/}$but not WT mice: In chronically hypercholesterolemic $\mathrm{ApoE}^{-/-}$mice, ageing associated to apparent immune system activation as evident by a higher number of circulating Ly6Chi monocytes (Fig.3A) and elevated plasma levels of interleukin (IL)12/23 (Fig.3B). The latter often secreted by activated monocytes/macrophages promote T helper (Th) 1 and Th17 priming of T-cells (Aggarwal, Ghilardi, Xie, de Sauvage, \& Gurney, 2003), which secrete IL17 amongst other cytokines and are considered main contributors to tissue inflammation (Damsker, Hansen, \& Caspi, 2010). Elevated IL17 plasma levels in aged $\mathrm{ApoE}^{-/-}$mice (Fig.3C) led us to test immune cell infiltration into brain tissue. 
FACS analyses revealed an increase of Ly6Chi pro-inflammatory monocytes (Fig.3D) and an overall higher percentage of $\mathrm{CD} 3+$ cells in brain tissue of aged vs. young ApoE ${ }^{-/-}$mice $(\mathbf{F i g . 3 E})$. Transcripts of key chemokines that regulate migration and infiltration of monocytes and macrophages, such as monocyte chemoattractant protein-1 (MCP-1) and chemokine ligand-2 (CXCL2) were drastically elevated in brain tissue of the aged cohort compared to young control mice (Table 2). Moreover, an mRNA expression pattern typical of a proinflammatory phenotype was predominant in brain tissue of aged $\mathrm{ApoE}^{-/-}$mice compared to young $\mathrm{ApoE}^{-/-}$ controls (Table 2). The degree of cytokine expression was brain region-dependent as evidenced by a markedly higher hippocampal than cortical IL12 expression in aged $\mathrm{ApoE}^{-/-}$mice compared to young controls (Table 2). IL23 also showed such region-specific expression patterns (Table 2). Besides, Arginase-1 (Arg-1) as commonly used marker for an alternatively activated macrophage phenotype presented with region-specific expression patterns: while cortical Arg-1 mRNA levels remained unaffected by age, the basally higher hippocampal Arg-1 expression significantly reduced with age (Table 2). Together, these data point to an apparent age-related inflammation in the hippocampus and may explain the more pronounced hippocampal-dependent memory impairment in aged $\mathrm{ApoE}^{-/-}$mice.

Although WT mice presented with an age-related increase of plasma cholesterol, BP (Table 1) and circulating Ly6Chi pro-inflammatory monocytes (Fig.3F), the percentage of Ly6Chi monocytes remained unaltered in the brain of aged WT mice (Fig.3G). Notably compared to WT mice, ApoE ${ }^{-/}$mice already showed a significantly higher proportion of circulating Ly6Chi cells at young age $(\mathbf{F i g . 3 F})$, suggesting a persistent pro-inflammatory state in chronically hypercholesterolemic $\mathrm{ApoE}^{-/-}$mice, which may promote immune infiltration into the brain with implications for memory function. Correspondingly, the proportion of brain Ly6Chi monocytes was higher in $\mathrm{ApoE}^{-/-}$mice compared to age-matched WT mice (Fig.3G). Furthermore, brain tissue of aged ApoE ${ }^{-{ }^{-}}$mice presented with significantly higher transcripts levels of chemokines MCP-1 and CXCL2 compared to agedmatched WT controls (Table S2). Taken together, these data suggest a key role for Ly6Chi monocyte activation and brain infiltration during chronic hypercholesterolemia where also memory deficits were observed.

3. Cholesterol- and/or BP-lowering therapy attenuates neuro-inflammation and memory deficits in aged ApoE $^{-/-}$mice. As chronically hypercholesterolemic $\mathrm{ApoE}^{-/-}$mice at 12 months of age presented with marginally elevated $\mathrm{BP}$ compared to 4 months old $\mathrm{ApoE}^{-/-}$mice, we subjected aged $\mathrm{ApoE}^{-/}$mice (i.e. 12 months of age) to lipid-lowering or BP-lowering therapy for 8 consecutive weeks, using the statin simvastatin $(5 \mathrm{mg} / \mathrm{kg} / \mathrm{d})$, the smooth muscle relaxant hydralazine $(0.5 \mathrm{mg} / \mathrm{kg} / \mathrm{d})$. Because we did not anticipate statin-mediated effects on BP, we also administered a combination of the two drugs to a group of animals (Fig.1B). The doses administered correspond to therapeutic doses used in the clinic $(10 \mathrm{mg} / \mathrm{kg} / \mathrm{d}$ and $20 \mathrm{mg} / \mathrm{kg} / \mathrm{d}$, respectively). All treatment strategies proved similarly effective in lowering the age-related elevated systolic BP: longitudinal BP measurements revealed markedly lower BP values in mice post treatment compared to the recorded pre-treatment values (Fig.S1). As expected, simvastatin treatment revealed significant cholesterol-lowering effects (Table S3). In line with other investigations (Patel et al., 2001; Takemoto et al., 2001), simvastatin treatment markedly reduced the age-related elevated heart-to-body weight ratio in our model without significantly affecting heart rate (Table S3). Interestingly, simvastatin's effects on heart hypertrophy and cholesterol were diminished in the presence of hydralazine (Table S3). Simvastatin revealed considerable anti-inflammatory capacity as evident by a reduction of circulating plasma IL12/23 levels (Fig.4A) and IL17 levels in vivo (Fig.4B). In the brain, simvastatin-treated mice revealed lower transcript levels of pro-inflammatory cytokines and chemokines, including IL6 and IL12, MCP-1 and CXCL2 (Table 3). Notably, hydralazine attenuated simvastatin's effects for some of the cytokines when administered in combination (Table 3). Treatment affected brain regions to different degrees as supported by statistically significant differences in hippocampal but not cortical IL12 expression between simvastatin- and hydralazine-treated groups (Table 3). Interestingly, IL23 revealed a different expression profile with significantly lower cortical IL23 expression in simvastatin-containing treatment groups while hippocampal IL23 expression only significantly changed when mice received simvastatin alone (Table 3). Moreover, the age-related increase of CD68 (monocyte/macrophage activation marker) was significantly lower in groups treated with simvastatin (Fig.4C). Since a majority of CD68+ cells were positive for ionized calciumbinding adapter molecule-1 (Iba-1; common microglia/macrophage marker) we assessed how age and treatment 
affected the number of total and CD68+ brain macrophages, and investigated their morphology by counting the numbers of ramified (= resting), intermediate and round (= activated) Iba-1+ cells. Ageing associated to increased numbers of CD68+ Iba1+ cells in two hippocampus regions (i.e. CA1 and DG) but not in the cortex of ApoE ${ }^{-/}$ mice (Fig.4D/E \& Fig.S2), indicative of region-specific augmentation of macrophage activation. Both hydralazine- and simvastatin-treated mice presented with lower numbers of CD68+ Iba1+ cells in the CA1 region of the hippocampus (Fig.4D); yet, only simvastatin revealed similar responses in the DG (Fig.4E). Neither drug affected CD68+ Iba-1+ cell counts in the cortex (Fig.S2). The total number of Iba-1+ cells significantly increased with age in the CA1 region of the hippocampus (Fig.4F) but not in DG or cortex (Fig.S3A/3B), suggesting region-specific proliferation of resident macrophages or accumulation of monocyte-derived macrophages. Yet, significant age-related changes in Iba-1+ cell morphology were only observed in the hippocampal DG region as evident by reduced proportion of ramified and increased amount of intermediate microglia (Table S4), adding to the notion that age elicits brain region-specific responses in chronically hypercholesterolemic mice. Treatment differently affected overall Iba-1+ cell number and morphology. While hydralazine treatment showed no apparent effects in any of the investigated brain regions (Table S4; Fig.4F; Fig.S3A/B), mice treated with simvastatin presented with a markedly lower overall count of Iba-1+ cells $(\mathbf{F i g . 4 F})$ and significantly reduced percentage of ramified and increased quantity of intermediate Iba-1+ cells compared to aged $\mathrm{ApoE}^{-/}$mice in the hippocampal CA1 region and in the cortex (Table S4). Interestingly, simvastatin-treated mice presented with overall lower numbers of Iba-1+ cells compared to young ApoE ${ }^{-/}$in both hippocampal DG and cortex (Fig.S3A/B) and marked changes in Iba-1+ cell morphology in all brain regions (Table S4). Similarly, combination treatment significantly reduced the number of ramified cells compared to young $\mathrm{ApoE}^{-/-}$mice in all brain regions investigated but markedly increased the proportion of activated cells compared to aged $\mathrm{ApoE}^{-/-}$in the hippocampal brain region without affecting overall Iba-1+ cell counts (Table S4; Fig.4F; Fig.S3A/B). Macrophages are highly plastic and adopt a variety of phenotypes on the scale between classically activated and alternatively activated phenotypes in response to various stimuli (Ma, Wang, Wang, \& Yang, 2017). Simvastatin treatment attenuated the expression of several markers characteristic for classical activation (i.e. TNF- $\alpha$, IL6, iNOS; Table 3) and significantly mitigated CD86 expression (Fig.4G) that has been shown to involve in pro-inflammatory phenotype-mediated retinal degeneration and Alzheimer's disease (AD) (F. Zhang et al., 2017; Zhou et al., 2017). Of markers typical of alternatively activated macrophages only Arg-1 was detected in cortical and hippocampal brain tissue in our model. Arg-1 mRNA expression significantly reduced with age in $\mathrm{ApoE}^{-/-}$mice, but aged mice treated with simvastatin presented with higher hippocampal Arg-1 mRNA expression (Table 3). Together, these data are suggestive of brain region-specific macrophage activation during ageing in $\mathrm{ApoE}^{-/-}$mice and an alternatively activated phenotype predominance after simvastatin treatment. Lastly, the age-related accumulation of CD3 was diminished in all treatment groups (Fig.4H).

In an open field test, only simvastatin treatment significantly improved age-related impaired mobility in $\mathrm{ApoE}^{-/-}$ mice (Fig.5A). Combination treatment with hydralazine revealed no apparent effects on mobility; yet, statistical analysis disclosed no difference to young control. Likewise, hippocampal-dependent memory function (Fig.5B) and spatial short-term memory function (Fig.5C) significantly improved in all treatment groups containing simvastatin. BDNF, an important regulator of white matter integrity, hippocampal long-term potentiation and consequently, learning and memory (Bekinschtein et al., 2008), was negatively affected by age in ApoE ${ }^{-/-}$mice, and only simvastatin treatment mitigated the age-related reduction of hippocampal BDNF expression (Fig.5D). Similarly, immune staining of hippocampal BDNF and the neuronal marker NeuN revealed evident differences between young and aged mice (Table S5, representative images shown in Fig.5Eii-vi). When normalized to the number of NeuN+ cells, BDNF expression was significantly lower in aged brains compared to young $\mathrm{ApoE}^{-/-}$ mice, and only significantly higher after treatment with simvastatin alone (Fig.5E). NeuN immunostaining, however, was significantly higher in all treatment groups that received simvastatin compared to untreated aged $\mathrm{ApoE}^{-/-}$mice (Table S5). Similar to the hippocampus, immune staining for BDNF in the cortex revealed significant differences between young and aged $\mathrm{ApoE}^{-/-}$mice, but all treatment regimens presented with high BDNF protein expression in this brain region (Table S5). Most notably, however, NeuN immune staining only significantly differed in hippocampus but not cortex where neither age nor treatment affected NeuN expression 
(Table S5), further supporting a prominent hippocampus-dependent memory impairment in aged chronically hypercholesterolemia $\mathrm{ApoE}^{-/-}$mice.

4. Simvastatin and hydralazine exert cell-specific effects. The observed differences of simvastatin and hydralazine responses in vivo, led us to evaluate their effects in vitro. Utilizing human monocytic cells (THP-1) and freshly isolated human monocytes allowed us to assess drug effects not only in monocytes but also in monocyte-derived macrophages. In both cell systems, hydralazine significantly induced cell activation (i.e. increased CD69 expression) that affected monocytes with a higher magnitude than macrophages (Fig.6Ai-iv). Simvastatin presented with no appreciable effects on CD69 expression (Fig.6Bi-ii). Similar to CD69, hydralazine but not simvastatin increased monocyte and macrophage CD3 expression (Fig.S4), which has been shown to involve in the delivery of pro-inflammatory cytokines (i.e. TNF- $\alpha$ ) by macrophages (Rodriguez-Cruz et al., 2019). Pro-inflammatory cytokine profiling in THP-1 cells revealed that LPS-induced augmentation of TNF- $\alpha$ protein expression only reversed with simvastatin but not hydralazine (Fig.6C). Interestingly, LPS-induced increases of intracellular IL6 protein abundance was not changed by simvastatin treatment but exacerbated in the presence of hydralazine (Fig.6Di-v). Hydralazine alone (without LPS pre-stimulation) disclosed similar proinflammatory effects (Fig.6Ei-iv). Different from monocytic cells, LPS-induced IL6 expression was similarly reduced in the presence of simvastatin or hydralazine in PMA-differentiated THP-1 cells (Fig.S5), further indicating cell type-specific drug responses. In support of this, LPS-induced elevation of TNF- $\alpha$ and IL6 secretion in murine bone-marrow-derived macrophages (BMDMs) reduced with both simvastatin and hydralazine treatment (Fig.6F \&G). Moreover, we detected lower surface expression of activation markers (i.e. CD86, CD80) in BMDMs of all treatment groups (Fig.S6). Additional flow cytometric analyses of monocytic or PMAdifferentiated THP-1 cells revealed a strong pro-inflammatory effect of hydralazine in monocytic cells (i.e. augmentation of LPS-associated CD14+ CD16+ surface expression; 2.5-fold; Fig.S7A/B) compared to PMAdifferentiated THP-1 cells. Interestingly, none of the drugs showed effects on T-cell activation (Fig.S8). Together, these data suggest cell type-specific drug effects that may benefit simvastatin as it exerted antiinflammatory effects in both monocytic cells and monocyte-derived macrophages. Hydralazine on the other hand, induced pro-inflammatory signatures especially in monocytic cells with potential implications for conditions characterized by elevated monocyte counts like chronic hypercholesterolemia, which may explain some of the effects we observe in vivo.

\section{Discussion}

The present study provides compelling evidence that chronic hypercholesterolemia majorly contributes to the development of memory impairment, involving pro-inflammatory processes. Our data imply that mainly the modulation of monocyte activation and thus, the stimulation of related pro-inflammatory signaling mediators critically determine the effectiveness of CVD therapeutics for improving impaired memory function associated to chronic hypercholesterolemia.

The herein established link between chronically elevated plasma cholesterol and the development of memory impairment in aged mice is based on findings, showing that only early exposure to elevated plasma cholesterol, indicative of chronic hypercholesterolemia results in reduced long-term and spatial memory function at an older age. This conclusion aligns with data obtained in epidemiological studies supporting a correlation between earlyor mid-life cholesterol levels to dementia in later life (Whitmer, Sidney, Selby, Johnston, \& Yaffe, 2005; Zambon et al., 2010). Similar to our findings obtained in aged WT mice, no association between cognitive decline and hypercholesterolemia was found in studies examining cholesterol levels in cohorts of older patients (Arvanitakis et al., 2008; Kivipelto \& Solomon, 2006). Interestingly, it has been shown that female $\mathrm{ApoE}^{-/-}$mice display greater cognitive impairment than male $\mathrm{ApoE}^{-/-}$mice (Lane-Donovan et al., 2016; Raber et al., 1998). The fact that female $\mathrm{ApoE}^{-/}$mice develop more severe atherosclerosis and vascular impairment earlier (Caligiuri, Nicoletti, Zhou, Tornberg, \& Hansson, 1999) supports the hypothesis that atherosclerosis contributes to cognitive dysfunction in this model. This is further signified by findings showing an absence of cognitive deficits in female brain-specific $\mathrm{ApoE}^{-/-}$mice that are characterized by absence of systemic hypercholesterolemia (Lane-Donovan et al., 2016). 
Thus, further investigations of sex-specific hypercholesterolemia effects on systemic and neuro-inflammation are needed.

Although hypercholesterolemia was generally accompanied by higher-than-normal $\mathrm{BP}$ in aged $\mathrm{ApoE}^{-/-}$mice, cholesterol-lowering rather than BP-lowering therapy significantly improved the impaired spatial memory of aged $\mathrm{ApoE}^{-/-}$mice. This further positions early life exposure to high cholesterol levels as major contributor to cognitive dysfunction in addition to potential BP-mediated structural and functional alterations in the brain (Meissner et al., 2016). Unlike statins for dyslipidemia treatment, hydralazine is not the first line medication for treating elevated BP. Nonetheless, hydralazine appears as first choice of BP-lowering therapy in numerous experimental studies where it has mostly been used preventatively to investigate the link between hypertension and inflammation or cognitive function (Itani et al., 2016; Iulita et al., 2018; Meissner et al., 2016), and is often used in the clinic to treat preeclampsia. Besides its vasorelaxant properties, it is thought to exert effects on the immune system, specifically on ICAM- and P-selectin- mediated T-cell transmigration (Rodrigues et al., 2008) and T-cell apoptosis (Ruiz-Magana et al., 2016). However, hydralazine-induced increases of cellular CD3-zeta chain content in T-cells are discussed to facilitate excessive drug-induced auto-immunity (Januchowski \& Jagodzinski, 2006). The pronounced enhancement of monocytic cell activation we observed in the presence of hydralazine might be resultant from reactive metabolites deriving from hydralazine oxidation (Uetrecht, 2005) or from hydralazine-mediated inhibition of DNA methyltransferase (Arce et al., 2006), which are postulated as major mechanisms in drug-induced auto-immunity might limit its potency to resolve neuro-inflammatory processes and thus, improve memory deficits in our model. Moreover, it might limit therapeutic efficacy of other drugs when administered in combination. This effect calls for the need to test for potential interactions between BP-lowering drugs of different nature and statins for potential consequences on immune regulation and cognitive impairment. It will be of utmost importance to further investigate the value of different classes of BP-lowering drugs in multi-morbid systems. The obvious benefits of angiotensin-converting enzyme inhibitors (ACEi) to attenuating amyloid-beta $(\mathrm{A} \beta)$ accumulation and glia-induced inflammation and improving cognitive function in AD mouse models (Asraf, Torika, Apte, \& Fleisher-Berkovich, 2018; Dong et al., 2011) have led to epidemiological studies that showed promising associations between the use of ACEi and cognitive function in AD patients.(de Oliveira, Bertolucci, Chen, \& Smith, 2014) Nonetheless, their potential to modulate inflammation is similarly controversially discussed as hydralazine's immune system effects (Coelho dos Santos et al., 2010; Goel et al., 2015). Thus, the circumstances under which BP-lowering drugs exert beneficial effects by slowing neuro-inflammation or cognitive decline remain to be determined especially, in the context of multimorbid phenotypes.

The activation of the immune system emerged as an important driver in the aged and vulnerable brain. Experimental studies verified the significance of inflammation in CVD progression (Berg et al., 2012; Meissner et al., 2017) and showed that inflammation associated to cardiovascular risk factors or CVD negatively affects cognitive function (Don-Doncow, Vanherle, et al., 2019; Don-Doncow, Zhang, Matuskova, \& Meissner, 2019; Faraco et al., 2018; Meissner et al., 2015). However, precise pro-inflammatory mechanisms contributing to accelerated cognitive decline and dementia risk require further elucidation. Similar to a study that links the Th17 - IL17 pathway to high dietary salt-induced cognitive impairment in mice (Faraco et al., 2018), we observe elevated IL17 plasma levels in cognitively impaired aged $\mathrm{ApoE}^{-/-}$mice with elevated cholesterol and BP levels, further signifying the link between circulating IL17 levels and memory performance as simvastatin-induced lowering of plasma cholesterol, BP and IL17 levels improved memory function. Another experimental study convincingly associates high fat diet-induced hypercholesterolemia in aged $\mathrm{ApoE}^{-/-}$mice not only to elevated plasma levels of IL6, TNF- $\alpha$, and IFN- $\gamma$ but also higher transcript levels of pro-inflammatory chemokine MCP1 in brain tissue of these mice (Dinh et al., 2017). In our study, we witness a similar increase of such key chemokines responsible for regulating migration and infiltration of monocytes in brain tissue of standard chowfed aged $\mathrm{ApoE}^{-/-}$but not WT mice. Consequently, the accumulation of pro-inflammatory Ly6Chi monocytes in the brain was absent in aged WT mice where plasma cholesterol levels only increase later in life and thus, positions pro-inflammatory monocytes as important contributors to neuro-inflammation emanating from chronic 
hypercholesterolemia. The concept of hypercholesterolemia-associated neuro-inflammation was recently investigated in aged hypercholesterolemic $\mathrm{ApoE}^{-/-}$mice where choroid plexus lipid accumulation induced leukocyte infiltration that extended to the adjacent brain parenchyma, demonstrating that lipid-triggered complement cascade activation promotes leukocyte infiltration into the choroid plexus with implications for immune system activation, cognitive decline in late onset $\mathrm{AD}$ and atherosclerotic plaque formation (Yin et al., 2019). Together with the finding that brain-specific ApoE deficiency protects from cognitive decline in the absence of hypercholesterolemia (Lane-Donovan et al., 2016), this further signifies the importance of chronic hypercholesterolemia in neuro-inflammatory and -degenerative processes observed in our model. The herein characterized brain region-specific neuro-inflammation together with distinct brain region-specific changes after cholesterol-lowering therapy, however, also suggest additional simvastatin-mediated mechanisms independent of cholesterol-lowering.

Our herein presented experimental strategy demonstrates that simvastatin therapy proves effective in reducing neuro-inflammation associated to chronic hypercholesterolemia in aged $\mathrm{ApoE}^{-/-}$mice. In particular, its beneficial hippocampal-specific effects on Iba-1+ cell number and morphology, CD86 and Arg-1 expression in our model point to additional therapeutic mechanisms independent of cholesterol-lowering. Simvastatin's antiinflammatory character might be resultant from its potency to regulating proliferation and activation of monocytes and macrophages (Alaarg et al., 2016; Rezaie-Majd et al., 2002), and to modulating myeloid cell phenotype (Yadav, Betts, \& Collman, 2016) and secretory function (Krysiak \& Okopien, 2013; McFarland, Davey, \& Anoopkumar-Dukie, 2017). The herein presented in vitro findings describe simvastatin's direct therapeutic effect on monocyte and macrophage activation and extent previous reports that showed an effective reduction of cytokine secretion in PMA-differentiated THP-1 cells pre-treated with simvastatin (McFarland et al., 2017). In its role as modulator for IL secretion from monocytes and macrophages, simvastatin was shown to indirectly inhibit IL17 secretion from CD4+ T-cells (Zhang, Jin, Peng, Ramgolam, \& Markovic-Plese, 2008). Moreover, simvastatin has been shown to directly inhibit the expression of a transcription factor responsible for controlling IL17 production in CD4+ T-cells (Zhang et al., 2008). These findings support our herein presented data showing a reduction of IL17 plasma levels in vivo only after simvastatin treatment. However, it remains to be determined whether the simvastatin effects in our model are mediated through direct modulation of Th17 responses, indirectly through modulation of myeloid cell activation or primarily through its lipid-lowering capacity. Because simvastatin has also been associated to Th2 immune response and neuronal recovery (Arora et al., 2006; Hakamada-Taguchi et al., 2003) we cannot exclude a potential therapeutic effect on T-cells in our model. Nonetheless, our results point to therapeutic effects through monocyte modulation, which aligns with studies conducted in patients at high risk for vascular events where a simvastatin-induced down-regulation of the angiotensin II type 1 receptor on monocytes but not T-cells significantly affected angiotensin II activity and thus, contributes to its anti-inflammatory profile and therapeutic effects in CVD (Marino et al., 2008). Moreover, in patients with hypercholesterolemia, simvastatin was shown to reduce monocyte secretory function (Krysiak \& Okopien, 2010, 2013). Most interestingly in respect to neurodegeneration is a study reporting a lowering of the CD14+CD16+ "intermediate" monocyte subset in purified monocytes isolated from peripheral blood of HIV patients in response to an ex vivo treatment with simvastatin, as this particular subset of monocytes is closely linked to HIV-associated neurocognitive disorders (Yadav et al., 2016).

In contrast to case reports discussing adverse effects of statins on cognitive function (Suraweera et al., 2016; Wagstaff et al., 2003), our study describes favorable outcomes for memory function in aged ApoE ${ }^{-/-}$mice after statin therapy, supporting findings from two large randomized control trials on simvastatin (Heart Protection Study Collaborative, 2007) and pravastatin (Shepherd et al., 2002) where no link between statin use and cognitive decline was observed. Although lipophilic statins, such as simvastatin are thought to cross the blood-brain barrier, leading to a reduction of cholesterol availability and thereby, disturbing the integrity of the neuronal and glial cell membrane (Miron et al., 2009), simvastatin treatment had no negative effects on hippocampal neurons, and significantly increased hippocampal and cortical BDNF expression in our model. Most beneficial effects of simvastatin in the brain are thought to root from the promotion of hippocampal neurogenesis, the inhibition of 
mesangial cell apoptosis (Qiao, Kang, \& Heo, 2011; Robin et al., 2014), the enhancement of neurotrophic factors, and the restriction of inflammation (Esposito et al., 2012). In light of this, simvastatin treatment markedly increased hippocampal expression of BDNF, which has been linked to improved functional recovery after stroke and the amelioration of depressive-like behavior (Ludka et al., 2016; J. Zhang et al., 2017), and may underlie the improvements in hippocampal-dependent memory function we observe in our model. Besides, preventative simvastatin treatment resulted in lower $\mathrm{A} \beta$ 40/42 levels in cerebrospinal fluid of AD mice, attenuated neuronal apoptosis and improved cognitive competence of the hippocampal network (Hu, Song, Fang, \& Li, 2018), suggesting that statin treatment may prevent the age-related, progressive neuropathy characteristic for $3 \times \mathrm{Tg}-\mathrm{AD}$ mice. Further investigation of $\mathrm{A} \beta$ accumulation in respect to neuro-inflammation and its modifiability by cholesterol-lowering or anti-inflammatory therapies would certainly elevate the impact of statin therapy beyond the field of CVD and associated target organ damage.

Taken together, our study convincingly links chronic hypercholesterolemia to myeloid cell activation, neuroinflammation and memory impairment, supporting the notion that early rather than late-life exposure to cardiovascular risk factors promotes the development of cognitive dysfunction. Cholesterol-lowering therapy provides effectiveness to improving memory function potentially by reducing monocyte-driven inflammatory events and hence, emerges as safe therapeutic strategy to control CVD-induced memory impairment and represents another benefit of statins in patients with hypercholesterolemia.

Funding: This work was supported by the following funding sources: The Knut and Alice Wallenberg foundation [2015.0030; AM]; Swedish Research Council [VR; 2017-01243; AM]; German Research Foundation [DFG; ME 4667/2-1; AM]; Åke Wibergs Stiftelse [M19-0380; AM]; Hedlund Stiftelse [M-2019-1101; AM], Inger Bendix Stiftelse [AM-2019-10; AM]; Stohnes Stiftelse [AM], Demensfonden [AM], and startup funds provided by the Wallenberg Centre for Molecular and Translational Medicine, University of Gothenburg, Sweden [AH].

Data Availability: The data underlying this article are available in the article and in its online supplementary material. 


\section{References}

Aggarwal, S., Ghilardi, N., Xie, M. H., de Sauvage, F. J., \& Gurney, A. L. (2003). Interleukin-23 promotes a distinct CD4 T cell activation state characterized by the production of interleukin-17. J Biol Chem, 278(3), 1910-1914. doi:10.1074/jbc.M207577200

Alaarg, A., Zheng, K. H., van der Valk, F. M., da Silva, A. E., Versloot, M., van Ufford, L. C., . . Hamers, A. A. (2016). Multiple pathway assessment to predict anti-atherogenic efficacy of drugs targeting macrophages in atherosclerotic plaques. Vascul Pharmacol, 82, 51-59. doi:10.1016/j.vph.2016.04.006

Arce, C., Segura-Pacheco, B., Perez-Cardenas, E., Taja-Chayeb, L., Candelaria, M., \& Duennas-Gonzalez, A. (2006). Hydralazine target: from blood vessels to the epigenome. J Transl Med, 4, 10. doi:10.1186/1479-58764-10

Arora, M., Chen, L., Paglia, M., Gallagher, I., Allen, J. E., Vyas, Y. M., . . Ray, P. (2006). Simvastatin promotes Th2-type responses through the induction of the chitinase family member Ym1 in dendritic cells. Proc Natl Acad Sci U S A, 103(20), 7777-7782. doi:10.1073/pnas.0508492103

Arvanitakis, Z., Schneider, J. A., Wilson, R. S., Bienias, J. L., Kelly, J. F., Evans, D. A., \& Bennett, D. A. (2008). Statins, incident Alzheimer disease, change in cognitive function, and neuropathology. Neurology, 70(19 Pt 2), 1795-1802. doi:10.1212/01.wnl.0000288181.00826.63

Asraf, K., Torika, N., Apte, R. N., \& Fleisher-Berkovich, S. (2018). Microglial Activation Is Modulated by Captopril: in Vitro and in Vivo Studies. Front Cell Neurosci, 12, 116. doi:10.3389/fncel.2018.00116 Baker, K. B., \& Kim, J. J. (2002). Effects of stress and hippocampal NMDA receptor antagonism on recognition memory in rats. Learn Mem, 9(2), 58-65. doi:10.1101/lm.46102

Bekinschtein, P., Cammarota, M., Katche, C., Slipczuk, L., Rossato, J. I., Goldin, A., . . Medina, J. H. (2008). BDNF is essential to promote persistence of long-term memory storage. Proc Natl Acad Sci U S A, 105(7), 2711-2716. doi:10.1073/pnas.0711863105

Berg, K. E., Ljungcrantz, I., Andersson, L., Bryngelsson, C., Hedblad, B., Fredrikson, G. N., . . Bjorkbacka, H. (2012). Elevated CD14++CD16- monocytes predict cardiovascular events. Circ Cardiovasc Genet, 5(1), 122-131. doi:10.1161/CIRCGENETICS.111.960385

Caligiuri, G., Nicoletti, A., Zhou, X., Tornberg, I., \& Hansson, G. K. (1999). Effects of sex and age on atherosclerosis and autoimmunity in apoE-deficient mice. Atherosclerosis, 145(2), 301-308.

doi:10.1016/s0021-9150(99)00081-7

Coelho dos Santos, J. S., Menezes, C. A., Villani, F. N., Magalhaes, L. M., Scharfstein, J., Gollob, K. J., \& Dutra, W. O. (2010). Captopril increases the intensity of monocyte infection by Trypanosoma cruzi and induces human T helper type 17 cells. Clin Exp Immunol, 162(3), 528-536. doi:10.1111/j.1365-2249.2010.04270.x Damsker, J. M., Hansen, A. M., \& Caspi, R. R. (2010). Th1 and Th17 cells: adversaries and collaborators. Ann N Y Acad Sci, 1183, 211-221. doi:10.1111/j.1749-6632.2009.05133.x

de Oliveira, F. F., Bertolucci, P. H., Chen, E. S., \& Smith, M. C. (2014). Brain-penetrating angiotensinconverting enzyme inhibitors and cognitive change in patients with dementia due to Alzheimer's disease. $J$ Alzheimers Dis, 42 Suppl 3, S321-324. doi:10.3233/JAD-132189

Dinh, Q. N., Chrissobolis, S., Diep, H., Chan, C. T., Ferens, D., Drummond, G. R., \& Sobey, C. G. (2017). Advanced atherosclerosis is associated with inflammation, vascular dysfunction and oxidative stress, but not hypertension. Pharmacol Res, 116, 70-76. doi:10.1016/j.phrs.2016.12.032

Don-Doncow, N., Vanherle, L., Zhang, Y., \& Meissner, A. (2019). T-Cell Accumulation in the Hypertensive Brain: A Role for Sphingosine-1-Phosphate-Mediated Chemotaxis. Int J Mol Sci, 20(3).

doi:10.3390/ijms20030537

Don-Doncow, N., Zhang, Y., Matuskova, H., \& Meissner, A. (2019). The emerging alliance of sphingosine-1phosphate signalling and immune cells: from basic mechanisms to implications in hypertension. $\mathrm{Br} \mathrm{J}$ Pharmacol, 176(12), 1989-2001. doi:10.1111/bph.14381

Dong, Y. F., Kataoka, K., Tokutomi, Y., Nako, H., Nakamura, T., Toyama, K., . . Kim-Mitsuyama, S. (2011). Perindopril, a centrally active angiotensin-converting enzyme inhibitor, prevents cognitive impairment in mouse models of Alzheimer's disease. FASEB J, 25(9), 2911-2920. doi:10.1096/fj.11-182873

Esposito, E., Rinaldi, B., Mazzon, E., Donniacuo, M., Impellizzeri, D., Paterniti, I., . . Cuzzocrea, S. (2012). Anti-inflammatory effect of simvastatin in an experimental model of spinal cord trauma: involvement of PPAR-alpha. J Neuroinflammation, 9, 81. doi:10.1186/1742-2094-9-81

Faraco, G., Brea, D., Garcia-Bonilla, L., Wang, G., Racchumi, G., Chang, H., . . Iadecola, C. (2018). Dietary salt promotes neurovascular and cognitive dysfunction through a gut-initiated TH17 response. Nat Neurosci, 21(2), 240-249. doi:10.1038/s41593-017-0059-z 
Gasecki, D., Kwarciany, M., Nyka, W., \& Narkiewicz, K. (2013). Hypertension, brain damage and cognitive decline. Curr Hypertens Rep, 15(6), 547-558. doi:10.1007/s11906-013-0398-4

Goel, R., Bhat, S. A., Rajasekar, N., Hanif, K., Nath, C., \& Shukla, R. (2015). Hypertension exacerbates predisposition to neurodegeneration and memory impairment in the presence of a neuroinflammatory stimulus: Protection by angiotensin converting enzyme inhibition. Pharmacol Biochem Behav, 133, 132-145. doi:10.1016/j.pbb.2015.04.002

Hajjar, I., Hart, M., Chen, Y. L., Mack, W., Milberg, W., Chui, H., \& Lipsitz, L. (2012). Effect of antihypertensive therapy on cognitive function in early executive cognitive impairment: a double-blind randomized clinical trial. Arch Intern Med, 172(5), 442-444. doi:10.1001/archinternmed.2011.1391

Hakamada-Taguchi, R., Uehara, Y., Kuribayashi, K., Numabe, A., Saito, K., Negoro, H., . . Kato, T. (2003). Inhibition of hydroxymethylglutaryl-coenzyme a reductase reduces Th1 development and promotes Th2 development. Circ Res, 93(10), 948-956. doi:10.1161/01.RES.0000101298.76864.14

Heart Protection Study Collaborative, G. (2007). Randomized trial of the effects of cholesterol-lowering with simvastatin on peripheral vascular and other major vascular outcomes in 20,536 people with peripheral arterial disease and other high-risk conditions. J Vasc Surg, 45(4), 645-654; discussion 653-644.

doi:10.1016/j.jvs.2006.12.054

Hu, X., Song, C., Fang, M., \& Li, C. (2018). Simvastatin inhibits the apoptosis of hippocampal cells in a mouse model of Alzheimer's disease. Exp Ther Med, 15(2), 1795-1802. doi:10.3892/etm.2017.5620

Itani, H. A., McMaster, W. G., Jr., Saleh, M. A., Nazarewicz, R. R., Mikolajczyk, T. P., Kaszuba, A. M., . . Guzik, T. J. (2016). Activation of Human T Cells in Hypertension: Studies of Humanized Mice and Hypertensive Humans. Hypertension, 68(1), 123-132. doi:10.1161/HYPERTENSIONAHA.116.07237 Iulita, M. F., Vallerand, D., Beauvillier, M., Haupert, N., C, A. U., Gagne, A., . . Girouard, H. (2018). Differential effect of angiotensin II and blood pressure on hippocampal inflammation in mice. $J$ Neuroinflammation, 15(1), 62. doi:10.1186/s12974-018-1090-z

Januchowski, R., \& Jagodzinski, P. P. (2006). Effect of hydralazine on CD3-zeta chain expression in Jurkat T cells. Adv Med Sci, 51, 178-180.

Jick, H., Zornberg, G. L., Jick, S. S., Seshadri, S., \& Drachman, D. A. (2000). Statins and the risk of dementia. Lancet, 356(9242), 1627-1631.

Kivipelto, M., \& Solomon, A. (2006). Cholesterol as a risk factor for Alzheimer's disease - epidemiological evidence. Acta Neurol Scand Suppl, 185, 50-57. doi:10.1111/j.1600-0404.2006.00685.x

Krysiak, R., \& Okopien, B. (2010). Different effects of simvastatin on ex vivo monocyte cytokine release in patients with hypercholesterolemia and impaired glucose tolerance. J Physiol Pharmacol, 61(6), 725-732. Krysiak, R., \& Okopien, B. (2013). Monocyte-suppressing effects of simvastatin in patients with isolated hypertriglyceridemia. Eur J Intern Med, 24(3), 255-259. doi:10.1016/j.ejim.2012.10.010

Lane-Donovan, C., Wong, W. M., Durakoglugil, M. S., Wasser, C. R., Jiang, S., Xian, X., \& Herz, J. (2016). Genetic Restoration of Plasma ApoE Improves Cognition and Partially Restores Synaptic Defects in ApoEDeficient Mice. J Neurosci, 36(39), 10141-10150. doi:10.1523/JNEUROSCI.1054-16.2016

Lidington, D., Fares, J. C., Uhl, F. E., Dinh, D. D., Kroetsch, J. T., Sauve, M., . . Bolz, S. S. (2019). CFTR Therapeutics Normalize Cerebral Perfusion Deficits in Mouse Models of Heart Failure and Subarachnoid Hemorrhage. JACC Basic Transl Sci, 4(8), 940-958. doi:10.1016/j.jacbts.2019.07.004

Ludka, F. K., Cunha, M. P., Dal-Cim, T., Binder, L. B., Constantino, L. C., Massari, C. M., . . Tasca, C. I. (2016). Atorvastatin Protects from Abeta1-40-Induced Cell Damage and Depressive-Like Behavior via ProBDNF Cleavage. Mol Neurobiol. doi:10.1007/s12035-016-0134-6

Ma, Y., Wang, J., Wang, Y., \& Yang, G. Y. (2017). The biphasic function of microglia in ischemic stroke. Prog Neurobiol, 157, 247-272. doi:10.1016/j.pneurobio.2016.01.005

Marino, F., Guasti, L., Cosentino, M., Rasini, E., Ferrari, M., Maio, R. C., . . Lecchini, S. (2008). Simvastatin treatment in subjects at high cardiovascular risk modulates AT1R expression on circulating monocytes and T lymphocytes. J Hypertens, 26(6), 1147-1155. doi:10.1097/HJH.0b013e3282f97dde

Masliah, E., Mallory, M., Ge, N., Alford, M., Veinbergs, I., \& Roses, A. D. (1995). Neurodegeneration in the central nervous system of apoE-deficient mice. Exp Neurol, 136(2), 107-122. doi:10.1006/exnr.1995.1088 McFarland, A. J., Davey, A. K., \& Anoopkumar-Dukie, S. (2017). Statins Reduce Lipopolysaccharide-Induced Cytokine and Inflammatory Mediator Release in an In Vitro Model of Microglial-Like Cells. Mediators Inflamm, 2017, 2582745. doi:10.1155/2017/2582745

McRae, A., Dahlstrom, A., Polinsky, R., \& Ling, E. A. (1993). Cerebrospinal fluid microglial antibodies: potential diagnostic markers for immune mechanisms in Alzheimer's disease. Behav Brain Res, 57(2), 225-234. Meissner, A. (2016). Hypertension and the Brain: A Risk Factor for More Than Heart Disease. Cerebrovasc Dis, 42(3-4), 255-262. doi:10.1159/000446082 
Meissner, A., Minnerup, J., Soria, G., \& Planas, A. M. (2016). Structural and functional brain alterations in a murine model of Angiotensin II-induced hypertension. J Neurochem. doi:10.1111/jnc.13905

Meissner, A., Miro, F., Jimenez-Altayo, F., Jurado, A., Vila, E., \& Planas, A. M. (2017). Sphingosine-1phosphate signalling-a key player in the pathogenesis of Angiotensin II-induced hypertension. Cardiovasc Res, 113(2), 123-133. doi:10.1093/cvr/cvw256

Meissner, A., Visanji, N. P., Momen, M. A., Feng, R., Francis, B. M., Bolz, S. S., \& Hazrati, L. N. (2015). Tumor Necrosis Factor-alpha Underlies Loss of Cortical Dendritic Spine Density in a Mouse Model of Congestive Heart Failure. J Am Heart Assoc, 4(5). doi:10.1161/JAHA.115.001920

Miron, V. E., Zehntner, S. P., Kuhlmann, T., Ludwin, S. K., Owens, T., Kennedy, T. E., . . Antel, J. P. (2009). Statin therapy inhibits remyelination in the central nervous system. Am J Pathol, 174(5), 1880-1890. doi:10.2353/ajpath.2009.080947

Moreira, E. L., de Oliveira, J., Nunes, J. C., Santos, D. B., Nunes, F. C., Vieira, D. S., . . Prediger, R. D. (2012). Age-related cognitive decline in hypercholesterolemic LDL receptor knockout mice (LDLr-/-): evidence of antioxidant imbalance and increased acetylcholinesterase activity in the prefrontal cortex. $J$ Alzheimers Dis, 32(2), 495-511. doi:10.3233/JAD-2012-120541

Mullen, L., Ferdjani, J., \& Sacre, S. (2015). Simvastatin inhibits TLR8 signaling in primary human monocytes and spontaneous TNF production from rheumatoid synovial membrane cultures. Mol Med.

doi:10.2119/molmed.2015.00154

Nair, A. B., \& Jacob, S. (2016). A simple practice guide for dose conversion between animals and human. $J$

Basic Clin Pharm, 7(2), 27-31. doi:10.4103/0976-0105.177703

Patel, R., Nagueh, S. F., Tsybouleva, N., Abdellatif, M., Lutucuta, S., Kopelen, H. A., . . Marian, A. J. (2001). Simvastatin induces regression of cardiac hypertrophy and fibrosis and improves cardiac function in a transgenic rabbit model of human hypertrophic cardiomyopathy. Circulation, 104(3), 317-324.

Peters, R., Beckett, N., Forette, F., Tuomilehto, J., Clarke, R., Ritchie, C., . . investigators, H. (2008). Incident dementia and blood pressure lowering in the Hypertension in the Very Elderly Trial cognitive function assessment (HYVET-COG): a double-blind, placebo controlled trial. Lancet Neurol, 7(8), 683-689. doi:10.1016/S1474-4422(08)70143-1

Pietschmann, P., Gollob, E., Brosch, S., Hahn, P., Kudlacek, S., Willheim, M., . . Tragl, K. H. (2003). The effect of age and gender on cytokine production by human peripheral blood mononuclear cells and markers of bone metabolism. Exp Gerontol, 38(10), 1119-1127.

Qiao, L. J., Kang, K. L., \& Heo, J. S. (2011). Simvastatin promotes osteogenic differentiation of mouse embryonic stem cells via canonical Wnt/beta-catenin signaling. Mol Cells, 32(5), 437-444. doi:10.1007/s10059011-0107-6

Raber, J., Wong, D., Buttini, M., Orth, M., Bellosta, S., Pitas, R. E., . . Mucke, L. (1998). Isoform-specific effects of human apolipoprotein $\mathrm{E}$ on brain function revealed in ApoE knockout mice: increased susceptibility of females. Proc Natl Acad Sci U S A, 95(18), 10914-10919. doi:10.1073/pnas.95.18.10914

Rezaie-Majd, A., Maca, T., Bucek, R. A., Valent, P., Muller, M. R., Husslein, P., . . Baghestanian, M. (2002). Simvastatin reduces expression of cytokines interleukin-6, interleukin-8, and monocyte chemoattractant protein-1 in circulating monocytes from hypercholesterolemic patients. Arterioscler Thromb Vasc Biol, 22(7), 1194-1199.

Rigaud, A. S., Olde-Rikkert, M. G., Hanon, O., Seux, M. L., \& Forette, F. (2002). Antihypertensive drugs and cognitive function. Curr Hypertens Rep, 4(3), 211-215.

Robin, N. C., Agoston, Z., Biechele, T. L., James, R. G., Berndt, J. D., \& Moon, R. T. (2014). Simvastatin promotes adult hippocampal neurogenesis by enhancing Wnt/beta-catenin signaling. Stem Cell Reports, 2(1), 917. doi:10.1016/j.stemcr.2013.11.002

Rockwood, K., Kirkland, S., Hogan, D. B., MacKnight, C., Merry, H., Verreault, R., . . McDowell, I. (2002). Use of lipid-lowering agents, indication bias, and the risk of dementia in community-dwelling elderly people. Arch Neurol, 59(2), 223-227.

Rodrigues, S. F., de Oliveira, M. A., dos Santos, R. A., Soares, A. G., de Cassia Tostes, R., Carvalho, M. H., \& Fortes, Z. B. (2008). Hydralazine reduces leukocyte migration through different mechanisms in spontaneously hypertensive and normotensive rats. Eur J Pharmacol, 589(1-3), 206-214. doi:10.1016/j.ejphar.2008.05.003 Rodriguez-Cruz, A., Vesin, D., Ramon-Luing, L., Zuniga, J., Quesniaux, V. F. J., Ryffel, B., . . Chavez-Galan, L. (2019). CD3(+) Macrophages Deliver Proinflammatory Cytokines by a CD3- and Transmembrane TNFDependent Pathway and Are Increased at the BCG-Infection Site. Front Immunol, 10, 2550.

doi:10.3389/fimmu.2019.02550 
Ruiz-Magana, M. J., Martinez-Aguilar, R., Lucendo, E., Campillo-Davo, D., Schulze-Osthoff, K., \& RuizRuiz, C. (2016). The antihypertensive drug hydralazine activates the intrinsic pathway of apoptosis and causes DNA damage in leukemic T cells. Oncotarget, 7(16), 21875-21886. doi:10.18632/oncotarget.7871

Shepherd, J., Blauw, G. J., Murphy, M. B., Bollen, E. L., Buckley, B. M., Cobbe, S. M., . . Risk, P. s. g. P. S. o. P. i. t. E. a. (2002). Pravastatin in elderly individuals at risk of vascular disease (PROSPER): a randomised controlled trial. Lancet, 360(9346), 1623-1630.

Sparrow, C. P., Burton, C. A., Hernandez, M., Mundt, S., Hassing, H., Patel, S., . . Wright, S. D. (2001). Simvastatin has anti-inflammatory and antiatherosclerotic activities independent of plasma cholesterol lowering. Arterioscler Thromb Vasc Biol, 21(1), 115-121.

Suraweera, C., de Silva, V., \& Hanwella, R. (2016). Simvastatin-induced cognitive dysfunction: two case reports. J Med Case Rep, 10, 83. doi:10.1186/s13256-016-0877-8

Takemoto, M., Node, K., Nakagami, H., Liao, Y., Grimm, M., Takemoto, Y., . . Liao, J. K. (2001). Statins as antioxidant therapy for preventing cardiac myocyte hypertrophy. J Clin Invest, 108(10), 1429-1437.

doi:10.1172/JCI13350

Tan, Z. S., \& Seshadri, S. (2010). Inflammation in the Alzheimer's disease cascade: culprit or innocent bystander? Alzheimers Res Ther, 2(2), 6. doi:10.1186/alzrt29

Uetrecht, J. (2005). Current trends in drug-induced autoimmunity. Autoimmun Rev, 4(5), 309-314.

doi:10.1016/j.autrev.2005.01.002

van Vliet, P. (2012). Cholesterol and late-life cognitive decline. J Alzheimers Dis, 30 Suppl 2, S147-162. doi:10.3233/JAD-2011-111028

Wagstaff, L. R., Mitton, M. W., Arvik, B. M., \& Doraiswamy, P. M. (2003). Statin-associated memory loss: analysis of 60 case reports and review of the literature. Pharmacotherapy, 23(7), 871-880.

Whitmer, R. A., Sidney, S., Selby, J., Johnston, S. C., \& Yaffe, K. (2005). Midlife cardiovascular risk factors and risk of dementia in late life. Neurology, 64(2), 277-281. doi:10.1212/01.WNL.0000149519.47454.F2

Wimo, A., Jonsson, L., Gustavsson, A., McDaid, D., Ersek, K., Georges, J., . . Valtonen, H. (2011). The economic impact of dementia in Europe in 2008-cost estimates from the Eurocode project. Int J Geriatr Psychiatry, 26(8), 825-832. doi:10.1002/gps.2610

Yadav, A., Betts, M. R., \& Collman, R. G. (2016). Statin modulation of monocyte phenotype and function: implications for HIV-1-associated neurocognitive disorders. J Neurovirol, 22(5), 584-596. doi:10.1007/s13365016-0433-8

Yin, C., Ackermann, S., Ma, Z., Mohanta, S. K., Zhang, C., Li, Y., . . Habenicht, A. J. R. (2019). ApoE attenuates unresolvable inflammation by complex formation with activated C1q. Nat Med, 25(3), 496-506. doi:10.1038/s41591-018-0336-8

Zambon, D., Quintana, M., Mata, P., Alonso, R., Benavent, J., Cruz-Sanchez, F., . . Pappolla, M. A. (2010). Higher incidence of mild cognitive impairment in familial hypercholesterolemia. Am J Med, 123(3), 267-274. doi:10.1016/j.amjmed.2009.08.015

Zhang, F., Zhong, R., Li, S., Fu, Z., Cheng, C., Cai, H., \& Le, W. (2017). Acute Hypoxia Induced an Imbalanced M1/M2 Activation of Microglia through NF-kappaB Signaling in Alzheimer's Disease Mice and Wild-Type Littermates. Front Aging Neurosci, 9, 282. doi:10.3389/fnagi.2017.00282

Zhang, J., Mu, X., Breker, D. A., Li, Y., Gao, Z., \& Huang, Y. (2017). Atorvastatin treatment is associated with increased BDNF level and improved functional recovery after atherothrombotic stroke. Int J Neurosci, 127(1), 92-97. doi:10.3109/00207454.2016.1146882

Zhang, X., Jin, J., Peng, X., Ramgolam, V. S., \& Markovic-Plese, S. (2008). Simvastatin inhibits IL-17 secretion by targeting multiple IL-17-regulatory cytokines and by inhibiting the expression of IL-17 transcription factor RORC in CD4+ lymphocytes. J Immunol, 180(10), 6988-6996.

Zhou, T., Huang, Z., Sun, X., Zhu, X., Zhou, L., Li, M., .. . He, C. (2017). Microglia Polarization with M1/M2 Phenotype Changes in rd1 Mouse Model of Retinal Degeneration. Front Neuroanat, 11, 77.

doi:10.3389/fnana.2017.00077 


\section{Tables}

Table 1: Hemodynamic data and plasma cholesterol levels of WT and ApoE ${ }^{-/ 2}$ mice. Systolic $\mathrm{BP}\left(\mathrm{BP}_{\mathrm{sys}}\right)$, diastolic $\mathrm{BP}\left(\mathrm{BP}_{\mathrm{dia}}\right)$ and heart rate $(\mathrm{HR})$ were measured in conscious mice using tail cuff plethysmography. Heart - body weight (BW) ratio calculated from animal weight $(\mathrm{g})$ and respective heart weight $(\mathrm{mg})$. Cholesterol levels were determined in plasma obtained from anaesthetized mice by ELISA. Values are expressed as mean +/- SEM. $N$ denotes number of independent biological replicates. $N=10$ per group; * denotes $P \leq 0.05$ relative to respective young, \& denotes $P \leq 0.05$ relative to aged of respective other group after two-way ANOVA followed by Sidak post hoc test.

\begin{tabular}{|c|c|c|c|c|}
\hline & $\begin{array}{c}\text { ApoE }^{-/-} \text {young } \\
\text { (4 months) }\end{array}$ & $\begin{array}{l}\text { ApoE }^{-/} \text {aged } \\
\text { (12 months) }\end{array}$ & $\begin{array}{l}\text { WT young } \\
\text { (4 months) }\end{array}$ & $\begin{array}{c}\text { WT aged } \\
\text { (12 months) }\end{array}$ \\
\hline $\mathbf{B P}_{\text {sys }}(\mathbf{m m H g})$ & $104.8 \pm 2.8$ & $133.2 \pm 4.4^{*}$ & $99.4 \pm 3.4$ & $114.6 \pm 1.7^{*}$ \\
\hline HR (bpm) & $489.1 \pm 9.1$ & $557.2 \pm 11.0^{*}$ & $458.9 \pm 17.7$ & $556.9 \pm 11.3^{*}$ \\
\hline Cholesterol (mg/L) & $98.3 \pm 2.4$ & $181.7 \pm 6.1^{*}$ & $74.2 \pm 0.8^{\&}$ & $99.8 \pm 2.6^{* \&}$ \\
\hline Heart BW ratio & $5.03 \pm 0.19$ & $5.91 \pm 0.26 *$ & $5.34 \pm 0.13$ & $5.48 \pm 0.27$ \\
\hline
\end{tabular}

Table 2: Brain mRNA expression of inflammatory markers in young and aged ApoE ${ }^{-/}$mice. mRNA expression of prominent inflammatory markers, including classical M1- and M2-like markers was determined in brain tissue isolated from 4- and 12-months old $\mathrm{ApoE}^{-/-}$mice using quantitative real-time PCR. Selected markers were tested in cortex and hippocampus fractions. Values are expressed as normalized to housekeeping gene expression and are shows as mean +/- SEM. $N$ denotes number of independent biological replicates. $N=5$ mice per group; * denotes $P \leq 0.05$ after single unpaired comparisons (two-tailed $t$-test).

\begin{tabular}{|c|c|c|}
\hline & $\begin{array}{c}\text { ApoE } \\
\text { (4 months) }\end{array}$ & $\begin{array}{c}\text { ApoE }^{-/} \text {aged } \\
(\mathbf{1 2} \text { months })\end{array}$ \\
\hline IL12 & $0.92 \pm 0.07$ & $5.12 \pm 0.59^{*}$ \\
\hline MCP-1 & $0.56 \pm 0.04$ & $7.55 \pm 0.68^{*}$ \\
\hline TNF-a & $1.04 \pm 0.12$ & $3.37 \pm 0.23^{*}$ \\
\hline IL6 & $1.26 \pm 0.17$ & $3.29 \pm 0.30^{*}$ \\
\hline CXCL2 & $0.68 \pm 0.17$ & $29.32 \pm 7.97^{*}$ \\
\hline iNOS & $0.32 \pm 0.03$ & $3.81 \pm 0.31^{*}$ \\
\hline \multicolumn{3}{|c|}{ cortex } \\
\hline IL12 & $1.02 \pm 0.05$ & $5.01 \pm 1.22^{*}$ \\
\hline IL23 & $0.20 \pm 0.07$ & $0.40 \pm 0.16$ \\
\hline Arg-1 & $0.52 \pm 0.08$ & $0.53 \pm 0.09$ \\
\hline & hippocampus \\
\hline
\end{tabular}




\begin{tabular}{|c|c|c|}
\hline IL12 & $1.28 \pm 0.56$ & $11.84 \pm 4.91^{*}$ \\
\hline IL23 & $0.51 \pm 0.09$ & $2.44 \pm 0.89^{*}$ \\
\hline Arg-1 & $3.31 \pm 0.66$ & $1.64 \pm 0.32^{*}$ \\
\hline
\end{tabular}

Table 3: Brain mRNA expression of pro-inflammatory cytokines and chemokines in ApoE ${ }^{-/}$mice after BPand cholesterol-lowering treatment. mRNA expression of prominent pro-inflammatory markers was determined in brain tissue isolated from the different experimental groups using quantitative real-time PCR. Selected markers were tested in cortex and hippocampus fractions. Values are expressed as normalized to housekeeping gene expression and shown as mean +/- SEM. $N$ denotes number of independent biological replicates. $N=5$ mice per group; * denotes $P \leq 0.05$ relative to young control, \& denotes $P \leq 0.05$ relative to aged control after one-way ANOVA followed by Tukey's post hoc test.

\begin{tabular}{|c|c|c|c|c|c|}
\hline target & $\begin{array}{l}\text { ApoE }{ }^{-/-} \text {young } \\
\text { (4 months) }\end{array}$ & $\begin{array}{l}\text { ApoE }{ }^{-/-} \text {aged } \\
(14 \text { months })\end{array}$ & $\begin{array}{l}\text { ApoE } E^{-/} \text {aged } \\
+ \text { hydralazine }\end{array}$ & $\begin{array}{l}\text { ApoE }{ }^{-/-} \text {aged } \\
+ \text { simvastatin }\end{array}$ & $\begin{array}{c}\text { ApoE }^{-/-} \text {aged } \\
\text { + hydralazine/simvastatin }\end{array}$ \\
\hline IL12 & $0.98 \pm 0.18$ & $16.84 \pm 2.29 *$ & $5.74 \pm 2.04 * \&$ & $1.39 \pm 0.39^{\&}$ & $6.15 \pm 2.48^{*}$ \\
\hline MCP-1 & $0.93 \pm 0.19$ & $9.11 \pm 2.64 *$ & $1.02 \pm 0.13^{\&}$ & $1.32 \pm 0.27^{\&}$ & $2.75 \pm 0.53 *^{\&}$ \\
\hline TNF-a & $0.94 \pm 0.09$ & $7.33 \pm 1.57^{*}$ & $2.16 \pm 0.38 * \&$ & $1.05 \pm 0.28^{\&}$ & $2.19 \pm 0.14 * \&$ \\
\hline IL6 & $1.14 \pm 0.13$ & $2.95 \pm 0.15^{*}$ & $2.130 \pm 0.37 *$ & $1.62 \pm 0.15^{\&}$ & $2.17 \pm 0.23 *$ \\
\hline CXCL2 & $0.68 \pm 0.17$ & $29.32 \pm 7.97 *$ & $11.60 \pm 7.85^{*}{ }^{\&}$ & $3.09 \pm 2.15^{\&}$ & $31.55 \pm 6.70^{*}$ \\
\hline iNOS & $1.00 \pm 0.17$ & $3.06 \pm 0.79 *$ & $2.38 \pm 0.58^{*^{\&}}$ & $1.89 \pm 0.48^{\&}$ & $2.59 \pm 0.62 *$ \\
\hline \multicolumn{6}{|c|}{ cortex } \\
\hline IL12 & $1.02 \pm 0.05$ & $5.07 \pm 1.15^{*}$ & $1.57 \pm 0.54^{\&}$ & $0.97 \pm 0.40^{\&}$ & $0.99 \pm 0.19^{\&}$ \\
\hline IL23 & $0.19 \pm 0.11$ & $1.16 \pm 0.30^{*}$ & $0.44 \pm 0.16^{\&}$ & $0.09 \pm 0.02^{\&}$ & $0.07 \pm 0.03^{\&}$ \\
\hline Arg-1 & $0.38 \pm 0.23$ & $0.11 \pm 0.06$ & $0.51 \pm 0.26$ & $0.43 \pm 0.14$ & $0.21 \pm 0.14$ \\
\hline \multicolumn{6}{|c|}{ hippocampus } \\
\hline IL12 & $1.35 \pm 0.35$ & $12.36 \pm 3.84 *$ & $6.74 \pm 1.59$ & $2.11 \pm 0.43^{\&}$ & $10.90 \pm 2.29 *$ \\
\hline IL23 & $1.00 \pm 0.54$ & $10.21 \pm 1.39 *$ & $4.48 \pm 0.57$ & $1.89 \pm 0.55^{\&}$ & $2.92 \pm 0.95$ \\
\hline Arg-1 & $6.41 \pm 1.07$ & $1.41 \pm 0.35^{*}$ & $0.83 \pm 0.26^{*}$ & $6.85 \pm 2.89^{\&}$ & $1.19 \pm 0.41^{*}$ \\
\hline
\end{tabular}




\section{Figure legends}

Figure 1: Schematic overview illustrating experimental setup. (A) Blood pressure (BP) and memory function were tested in 4- and 12-months old ApoE ${ }^{-/-}$and WT mice simultaneously. At termination, immune status in blood and brain was assessed using flow cytometry, ELISA and qPCR. Synaptic marker expression was determined by Western blotting (WB) and qPCR. This approach aimed at characterizing aging in the $\mathrm{ApoE}^{-/-}$model in respect to plasma cholesterol levels, BP, systemic and neuro-inflammation as well as memory performance. (B) 12months old ApoE ${ }^{-/-}$mice (associated with chronic hypercholesterolemia, increased BP, augmented systemic and neuro-inflammation and memory deficits) were subjected to 8-weeks cholesterol-lowering therapy (i.e. simvastatin), BP-lowering therapy (i.e. hydralazine) or a combination of both. BP was assessed longitudinally to monitor the effect of the different treatment regimens on BP. Memory function was assessed at 14 months of age. At termination, plasma cholesterol levels were determined by ELISA and systemic and neuroinflammation were assessed by ELISA, qPCR, WB and immunofluorescence to characterize the effects of the different treatment regimens on the different signatures we identified to be altered in this model (i.e. plasma cholesterol, BP, inflammatory status and memory function).

Figure 2: Chronic hypercholesterolemia impairs memory function. (A) Schematic illustration of novel object recognition task with 24-h delay interval. Recognition index (RI) describing hippocampus-dependent long-term memory function in young and aged $\mathrm{WT}$ and $\mathrm{ApoE}^{-/-}$mice $(\mathrm{N}=10$ per group; some animals were excluded due to total object exploration times below 20s). The pink dotted line indicates the point where the animal has no preference for either object. (B) Schematic illustration of an object placement test with a 5 min delay interval. RI describing spatial short-term memory function in young and aged WT and $\mathrm{ApoE}^{-{ }^{--}}$mice $(\mathrm{N}=10$ per group; some animals were excluded due to total object exploration times below 20s). The pink dotted line indicates the point where the animal has no preference for either object. (C) Western blot analysis displaying unchanged pre- and post-synaptic protein (SNAP-25 and PSD-95) expression levels in whole brain tissue lysates of young and aged ApoE $^{--}$mice ( $\mathrm{N}=4$ for young and $\mathrm{N}=5$ for aged $\mathrm{ApoE}^{--}$). (D) Brain region-specific mRNA expression analysis revealing reduced PSD-95 expression levels in aged $\mathrm{ApoE}^{-/-}$mice $(\mathrm{N}=4$ for young cortex and $\mathrm{N}=5$ for young hippocampus and aged cortex and hippocampus). $\mathrm{N}$ denotes number of independent biological replicates. In A$\mathbf{D}$, * denotes $\mathrm{P} \leq 0.05$ relative to young control of same genotype, \& denotes $\mathrm{P} \leq 0.05$ relative to WT aged after two-way ANOVA followed by Sidak post hoc testing.

Figure 3: Immune system activation leads to leukocyte infiltration into the brain of aged ApoE ${ }^{-/-}$mice. (A) Percentage of circulating pro-inflammatory Ly6Chi monocytes determined by flow cytometry of young and aged $\mathrm{ApoE}^{-/}$mice and representative images showing typical dot plots. (B) Plasma levels of pro-inflammatory IL12/23 and (C) IL17 of young and aged $\mathrm{ApoE}^{-/-}$mice determined by ELISA ( $\mathrm{N}=10$ per group; some samples failed to return a signal and were excluded from analysis). (D) Percentage of Ly6Chi monocytes in brain tissue of young and aged $\mathrm{ApoE}^{-/-}$mice analyzed by flow cytometry and representative dot plots ( $\mathrm{N}=10$ per group; some samples were excluded from analysis due to heavy myelin contamination). (E) Percentage of CD3+ T-cells in brain tissue of young and aged $\mathrm{ApoE}^{-{ }^{-}}$mice analyzed by flow cytometry and representative dot plots $(\mathrm{N}=10$ per group; some samples were excluded from analysis due to heavy myelin contamination). (F) Percentage of circulating proinflammatory Ly6Chi monocytes in young and aged WT mice ( $\mathrm{N}=10$ per group) compared to ApoE ${ }^{-/-}$mice determined by flow cytometry and representative images showing dot plots for WT mice. (G) Percentage of Ly6Chi monocytes in brain tissue of young and aged WT mice ( $\mathrm{N}=10$ per group) compared to ApoE ${ }^{-/-}$mice analyzed by flow cytometry and representative images showing dot plots for WT mice. N denotes number of independent biological replicates. In A-E, * denotes $\mathrm{P} \leq 0.05$ for single, unpaired comparisons; in $\mathbf{F - G}$, * denotes $\mathrm{P} \leq 0.05$ relative to young control of same genotype, $\&$ denotes $\mathrm{P} \leq 0.05$ relative to $\mathrm{WT}$ aged, and + denotes $\mathrm{P} \leq$ 0.05 relative to WT young after two-way ANOVA followed by Sidak post hoc testing.

Figure 4: Simvastatin treatment attenuates systemic and neuro-inflammation in aged ApoE ${ }^{-/}$mice. (A) Effect of cholesterol- and BP-lowering treatment (hydralazine - green circle, simvastatin - pink circles, combination orange circles) on plasma levels of pro-inflammatory IL12/23 and (B) IL17 determined by ELISA (N=10 per 
group and $\mathrm{N}=8$ for aged + combination treatment; some samples failed to return a signal and were excluded from analysis). (C) Effect of cholesterol- and BP-lowering treatment on CD68 mRNA expression in whole brain extracts of aged $\mathrm{ApoE}^{-/-}$mice ( $\mathrm{N}=5$ per group). (D) Effect of cholesterol- and BP-lowering treatment on the number of $\mathrm{CD} 68+\mathrm{Iba} 1+$ cells in the $\mathrm{CA} 1$ region of the hippocampus of aged $\mathrm{ApoE}^{-/-}$mice $(\mathrm{N}=3$ for young and aged + combination treatment; $\mathrm{N}=4$ for aged control and simvastatin treatment; $\mathrm{N}=5$ for hydralazine treatment; the two hemispheres were counted separately. (E) Effect of cholesterol- and BP-lowering treatment on the CD68+ Iba1+ cells in the DG region of the hippocampus of aged $\mathrm{ApoE}^{-/}$mice $(\mathrm{N}=3$ for young and aged + combination treatment; $\mathrm{N}=4$ for aged control and simvastatin treatment; $\mathrm{N}=5$ for hydralazine treatment; the two hemispheres were counted separately). (F) Effect of cholesterol- and BP-lowering treatment on the total Iba1+ cell count in the $\mathrm{CA} 1$ region of the hippocampus of aged $\mathrm{ApoE}^{-/-}$mice $(\mathrm{N}=3$ for young and aged + combination treatment; $\mathrm{N}=4$ for aged control and simvastatin treatment; $\mathrm{N}=5$ for hydralazine treatment; the two hemispheres were counted separately except for a sample in the aged + hydralazine group where one hippocampus region was not analyzable). (G) Effect of cholesterol- and BP-lowering treatment on CD86 mRNA expression in the hippocampus of aged $\mathrm{ApoE}^{-/}$mice ( $\mathrm{N}=5$ per group). (H) Effect of cholesterol- and BP-lowering treatment on $\mathrm{CD} 3$ protein expression in whole brain lysates of aged $\mathrm{ApoE}^{-/-}$mice $(\mathrm{N}=4$ for hydralazine- and combinationtreated groups and $\mathrm{N}=5$ for control and simvastatin-treated groups). Inset showing representative protein expression pattern. $\mathrm{N}$ denotes number of independent biological replicates. In A-C and $\mathbf{G}-\mathbf{H}$, * denotes $\mathbf{P} \leq 0.05$ relative to young control, \& denotes $\mathrm{P} \leq 0.05$ relative to aged control after one-way ANOVA followed by Tukey's post hoc testing. In $\mathbf{F}, *$ denotes $\mathrm{P} \leq 0.05$ relative to young control, \& denotes $\mathrm{P} \leq 0.05$ relative to aged control after Kruskal-Wallis followed by Dunn's post hoc testing.

Figure 5: Simvastatin mitigates impaired memory function of aged ApoE ${ }^{-/}$mice. (A) Quantification of open field test assessing mobility in aged $\mathrm{ApoE}^{-/-}$mice treated with hydralazine (green circles), simvastatin (pink circles) and a combination of both (orange circles) in comparison to young and aged control mice (open circles). ( $\mathrm{N}=10$ per group; some animals were excluded due to total mobile times below 20s). Representative images showing (i) young control, (ii) aged control, (iii) aged + hydralazine, (iv) aged + simvastatin, and (v) aged + hydralazine/simvastatin. (B) Effect of lipid- and BP lowering treatment on long-term memory function, and on (C) spatial long-term memory function. ( $\mathrm{N}=10$ per group; some animals were excluded due to total object exploration times below 20s). The pink dotted line indicates the point where the animal has no preference for either object. (D) Effect of lipid- and BP lowering treatment on hippocampal BDNF mRNA expression (N=5 for young, aged and hydralazine-treated groups; $\mathrm{N}=4$ for simvastatin- and combination-treated groups). (E) Representative images of BDNF (green) and NeuN (red) immune staining showing a hippocampal CA region as illustrated in (i) HE-stained coronal brain section of an aged ApoE ${ }^{-/-}$mouse: (ii) aged control, (iii) aged + hydralazine, (iv) aged + simvastatin, and (v) aged + combined treatment. Quantification of BDNF-NeuN ratio comparing young and aged $\mathrm{ApoE}^{-/}$mice with treatment groups $(\mathrm{N}=3$ for young and aged + combination treatment; $\mathrm{N}=4$ for aged control and simvastatin treatment; $\mathrm{N}=5$ for hydralazine treatment). $\mathrm{N}$ denotes number of independent biological replicates. In $\mathbf{A},{ }^{*}$ denotes $\mathrm{P} \leq 0.05$ relative to young control, \& denotes $\mathrm{P} \leq 0.05$ relative to aged control after Kruskal-Wallis followed by Dunn's post hoc testing. In B-D, * denotes $\mathrm{P} \leq 0.05$ relative to young control, \& denotes $\mathrm{P} \leq 0.05$ relative to aged control after one-way ANOVA followed by Tukey's post hoc testing.

Figure 6: Simvastatin reduces monocyte activation. (A) Degree of myeloid cell activation in response to hydralazine determined by flow cytometric assessment of CD69 surface expression (expressed in fold change compared to control to include results from eight experimental groups in the graph; non-normalized data can be found in Supplemental Table 6) in human monocytic THP-1 cells and PMA-treated monocyte-derived macrophages compared to human primary monocytes and monocyte-derived macrophages ( $\mathrm{N}=3$ per group). Representative histograms showing the typical CD69+ cell distribution. (B) Degree of myeloid cell activation in response to simvastatin determined by flow cytometric assessment of CD69 surface expression (expressed in fold change compared to control to include results from four experimental groups in the graph; non-normalized data can be found in Supplemental Table 6) in human primary monocytes and monocyte-derived macrophages ( $\mathrm{N}=3$ 
per group). Representative histograms showing the typical CD69+ cell distribution. (C) Effect of hydralazine and simvastatin on LPS-induced TNF- $\alpha$ protein expression in human monocytic THP-1 cells determined by WB ( $\mathrm{N}=4$ in control and combination-treated groups; N=5 in LPS control, hydralazine- and simvastatin-treated groups). (D) Effect of hydralazine and simvastatin on LPS-induced intracellular IL6 expression in human monocytic THP-1 cells determined by flow cytometry ( $\mathrm{N}=5$ per group). Representative dot plot showing the typical IL6+ cell distribution. (E) Effect of hydralazine and simvastatin on intracellular IL6 expression in human monocytic THP-1 cells determined by flow cytometry ( $=5$ per group). Representative dot plot showing the typical IL6+ cell distribution. (F) Effect of hydralazine and simvastatin on LPS-mediated TNF- $\alpha$ and (G) IL6 release in murine bone marrow-derived macrophages assessed by ELISA ( $\mathrm{N}=4$ for untreated control and hydralazine-treated cells, $\mathrm{N}=8$ for LPS-treated control and simvastatin-treated cells). $\mathrm{N}$ denotes number of independent biological replicates. In $\mathbf{A},{ }^{*}$ denotes $\mathrm{P} \leq 0.05$ relative to respective control for unpaired $\mathrm{t}$-test; in $\mathbf{C}$ $\mathbf{F} *$ denotes $\mathrm{P} \leq 0.05$ relative to control, \& denotes $\mathrm{P} \leq 0.05$ relative to LPS-treated control after one-way ANOVA followed by Tukey's post hoc testing. 
A

ApoE-/WT
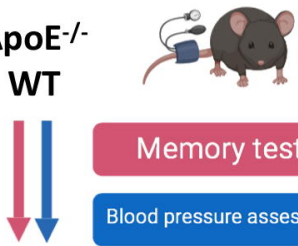

\section{Memory testing}

Blood pressure assessment

Months

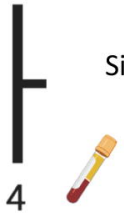

"young"

Simultaneously assessed

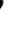

B
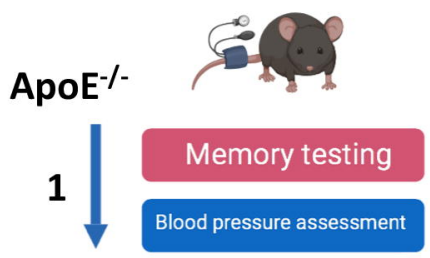

Months

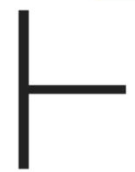

12

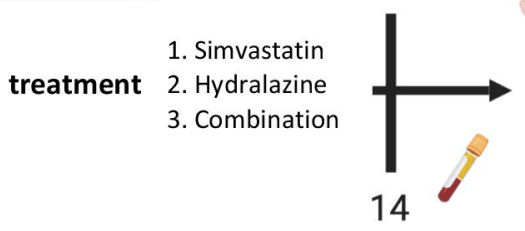

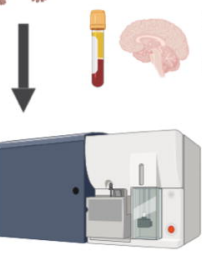

Flow cytometry

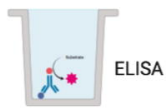

"aged"
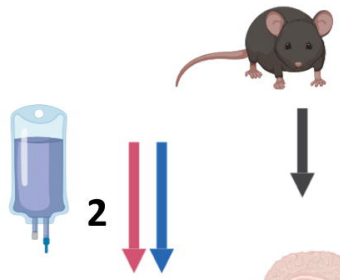

WB

IF

qPCR

ELISA 
A
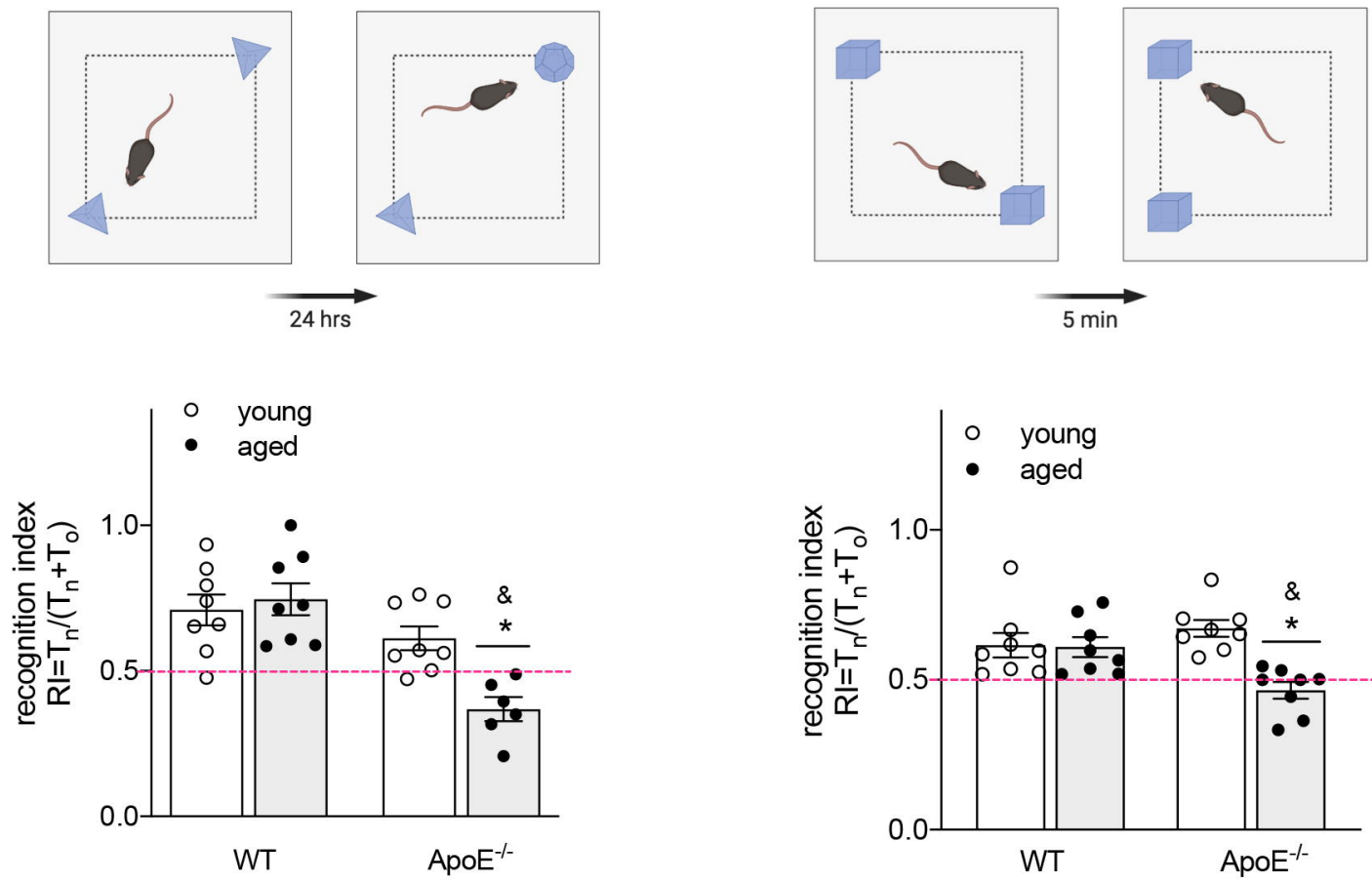

C
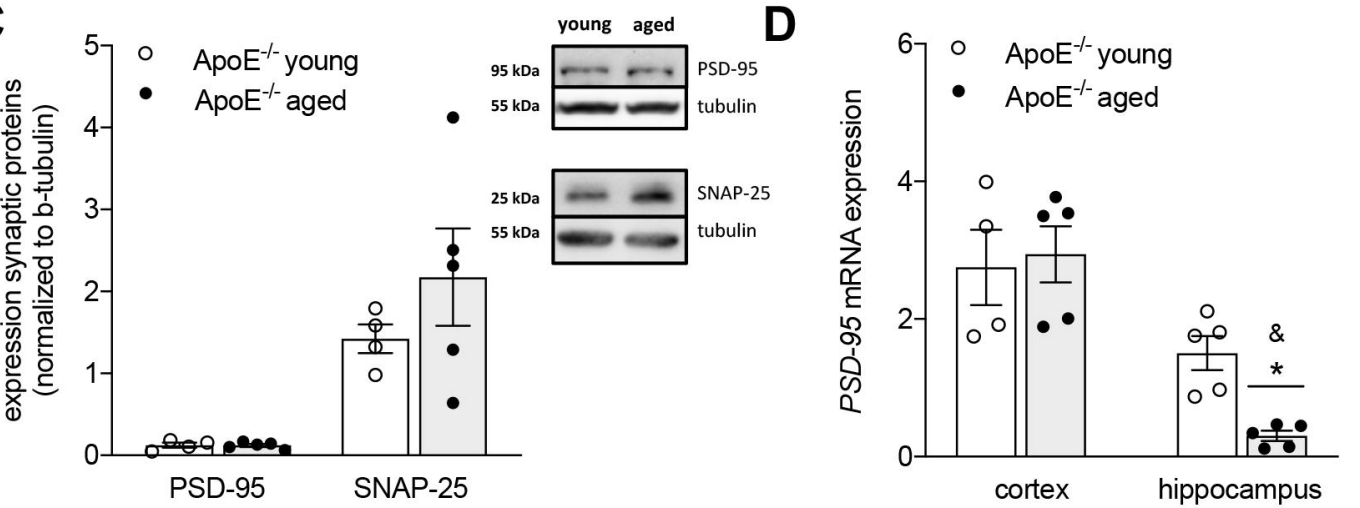
A
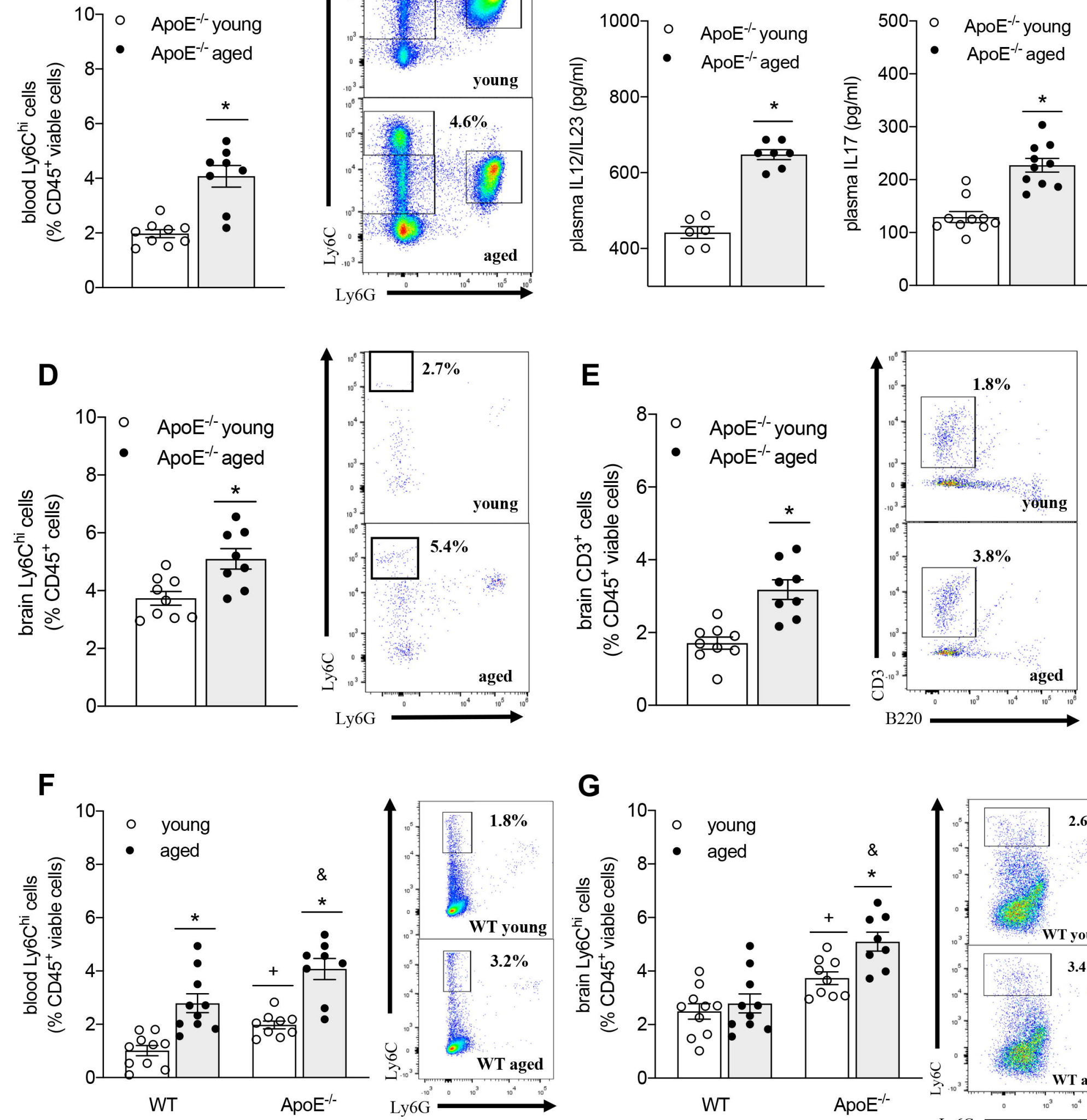

B

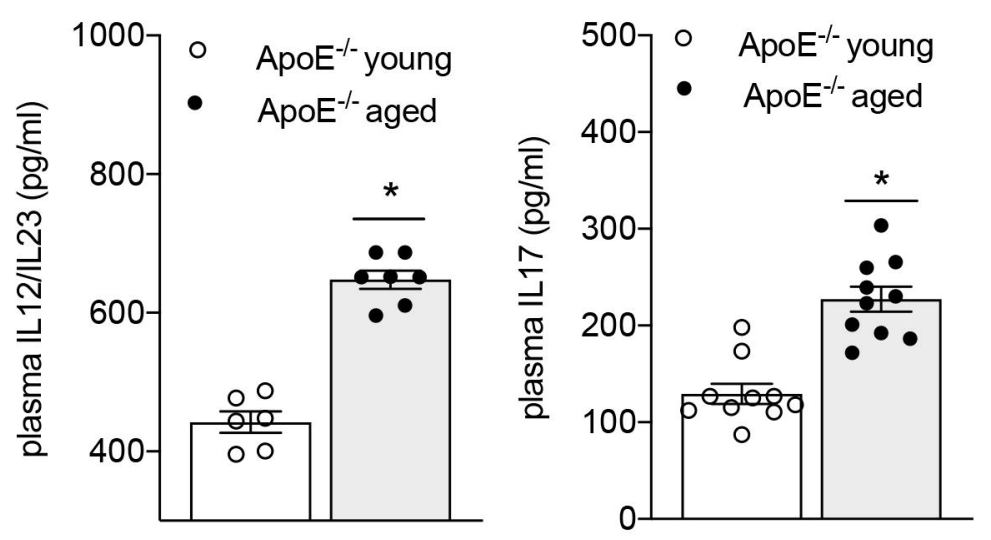

Ly6G

aged

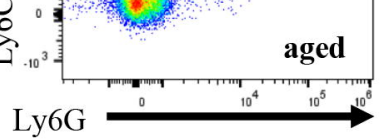

G

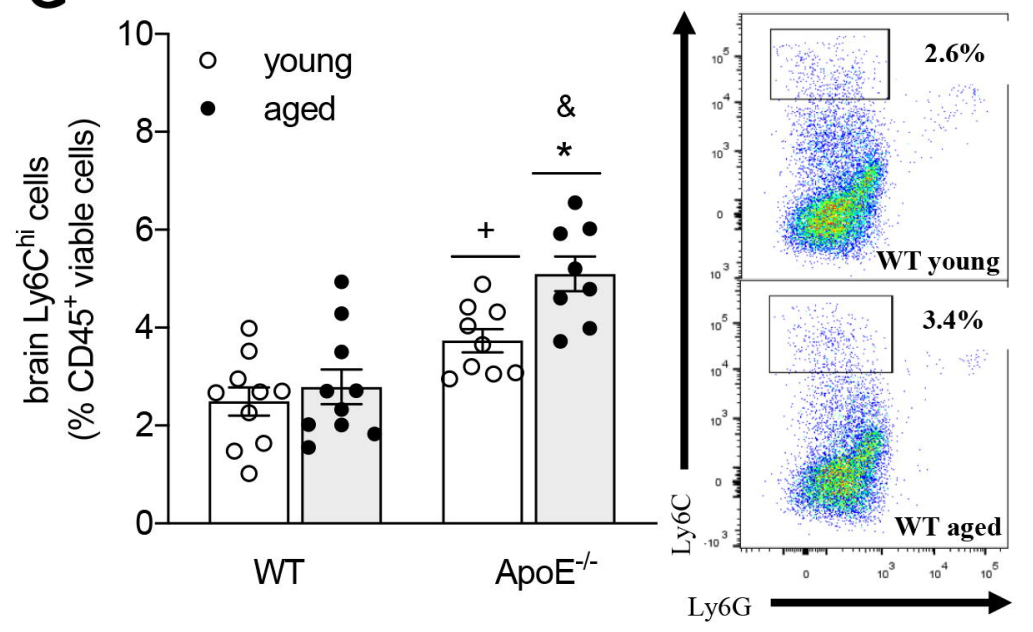


A $\quad$ B

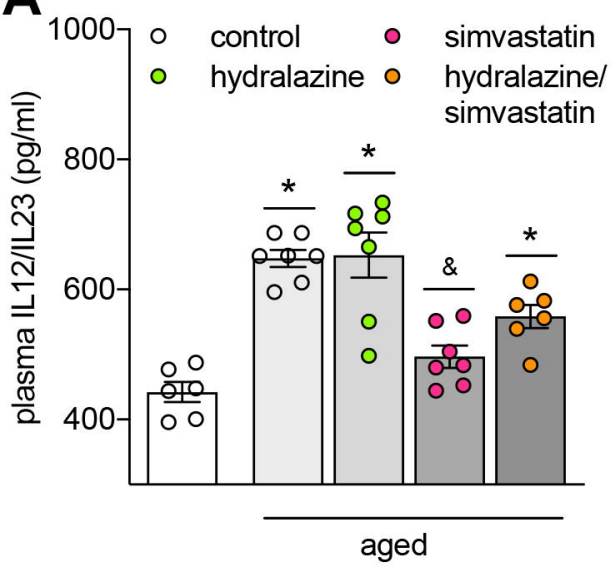

D

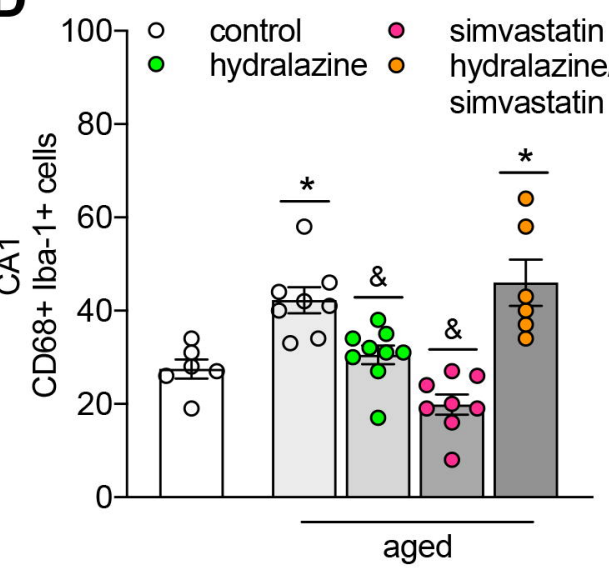

G

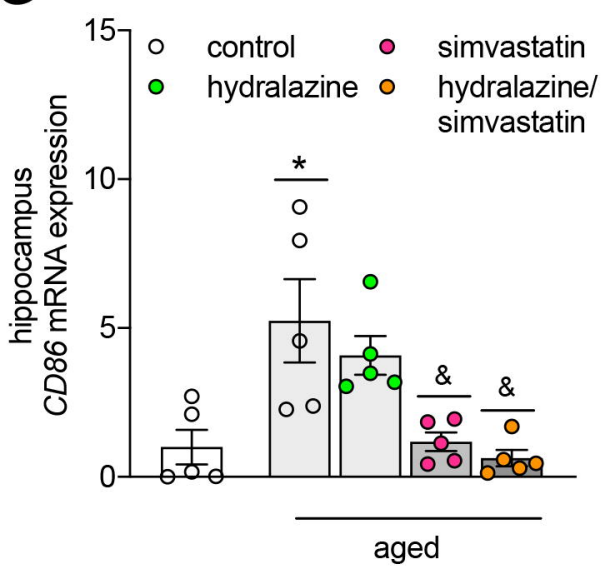

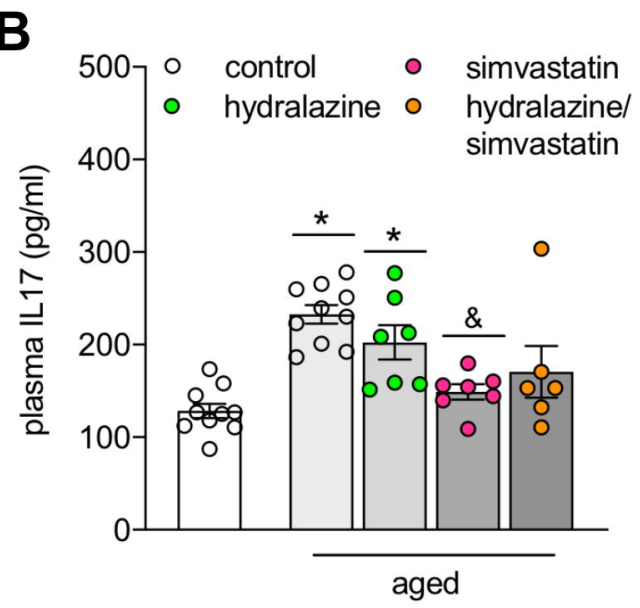

E

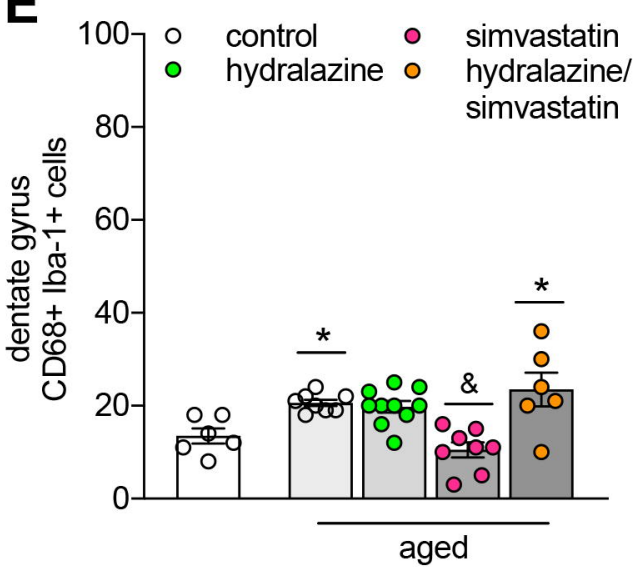

H

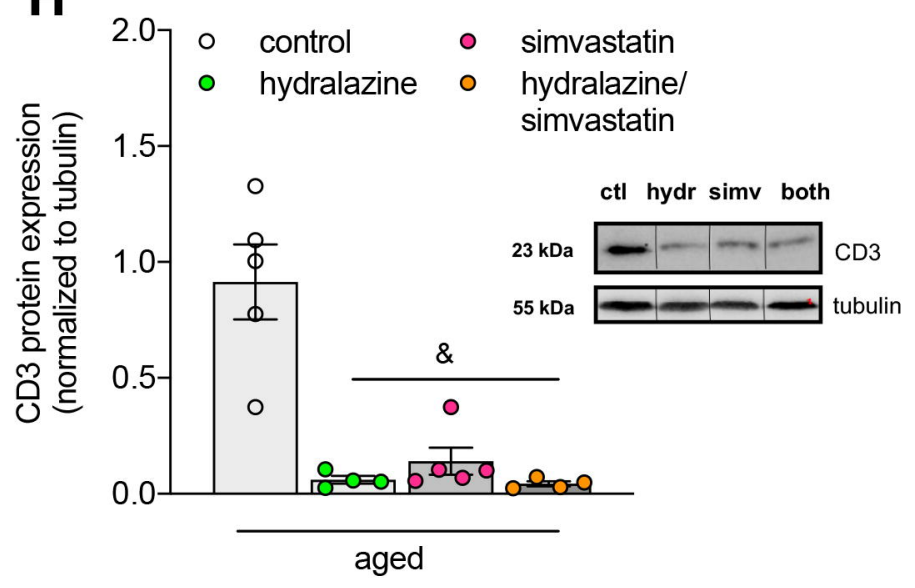

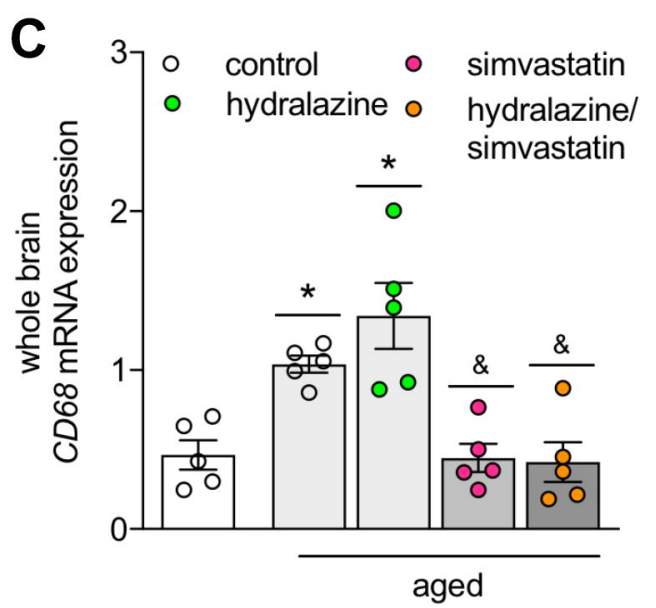

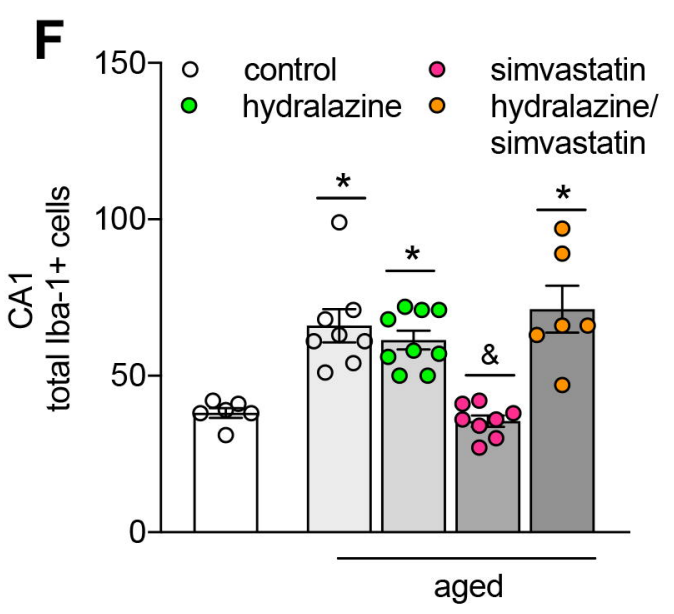


A

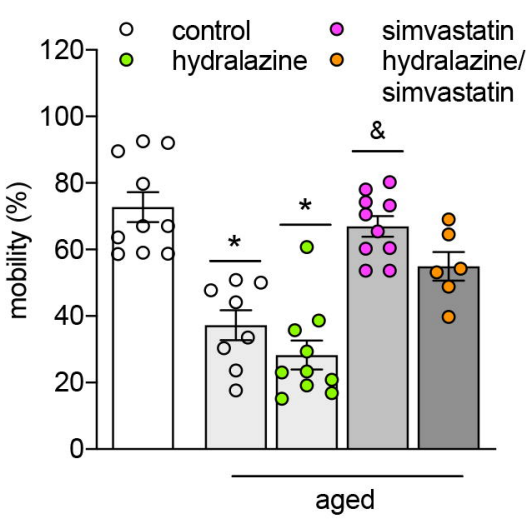

B
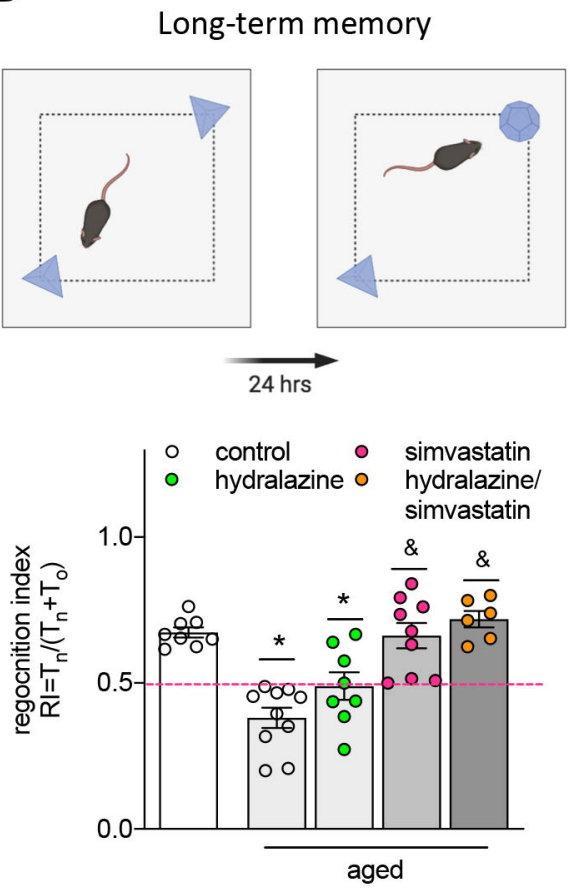

D

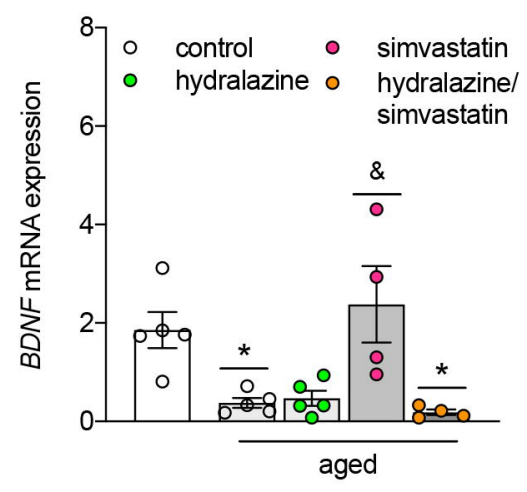

open field test
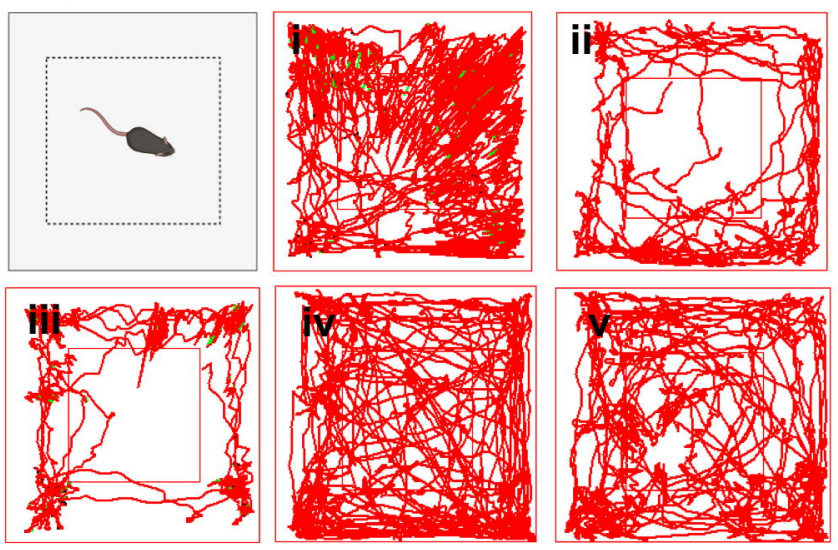

C

\section{Spatial short-term memory}
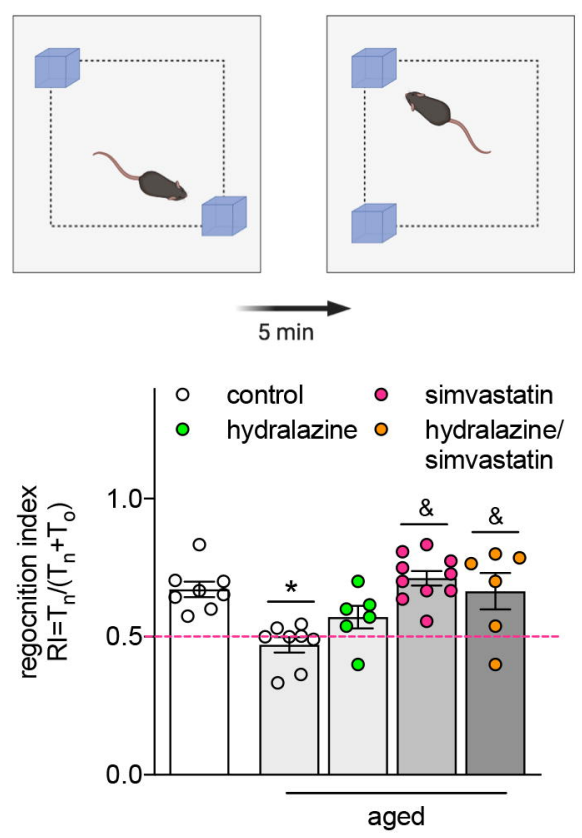

E
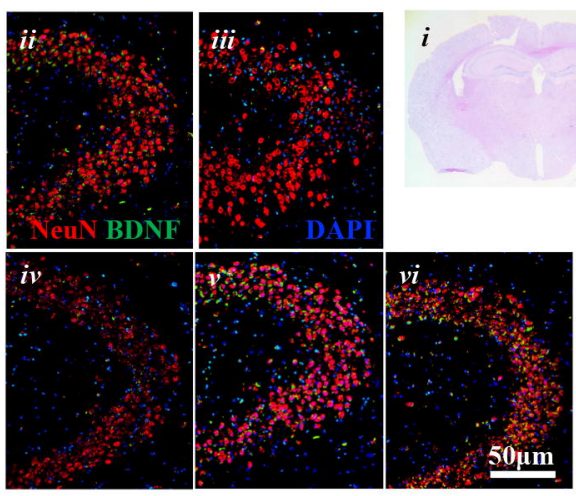
A

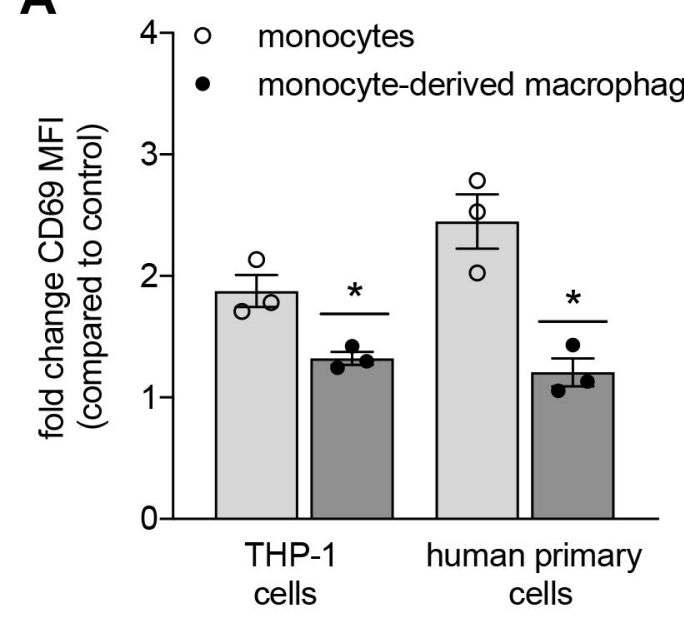

c

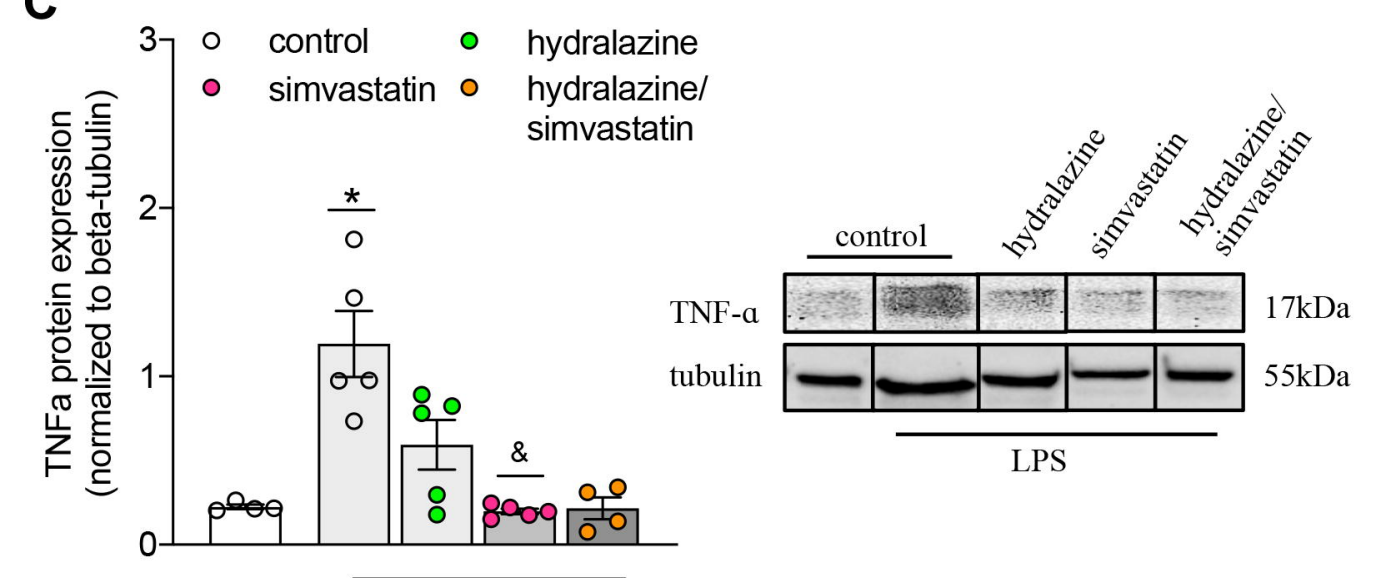

LPS

\section{E}
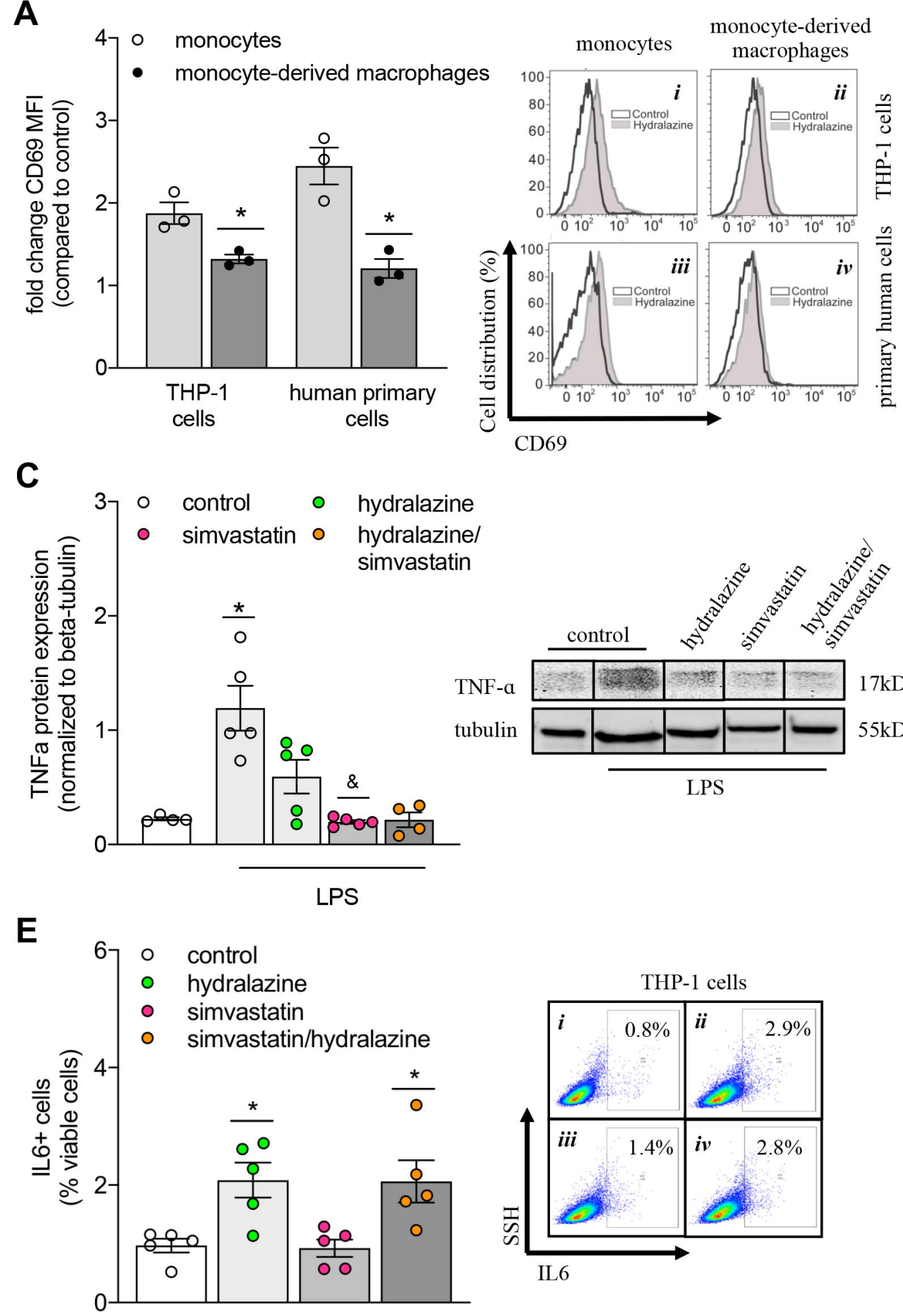

B $\quad{ }^{2.0} 7^{\circ}$ monocytes

- monocyte-derived macrophages

䒚 $\widehat{0} 1.5-$

\&

Oे용

o.

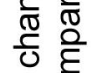

흔 훙 0.5

0.0
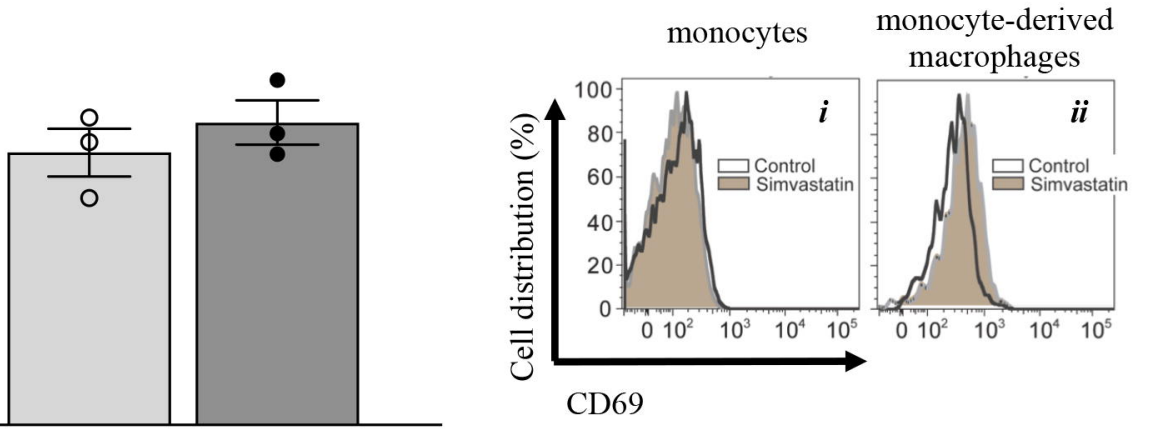

D
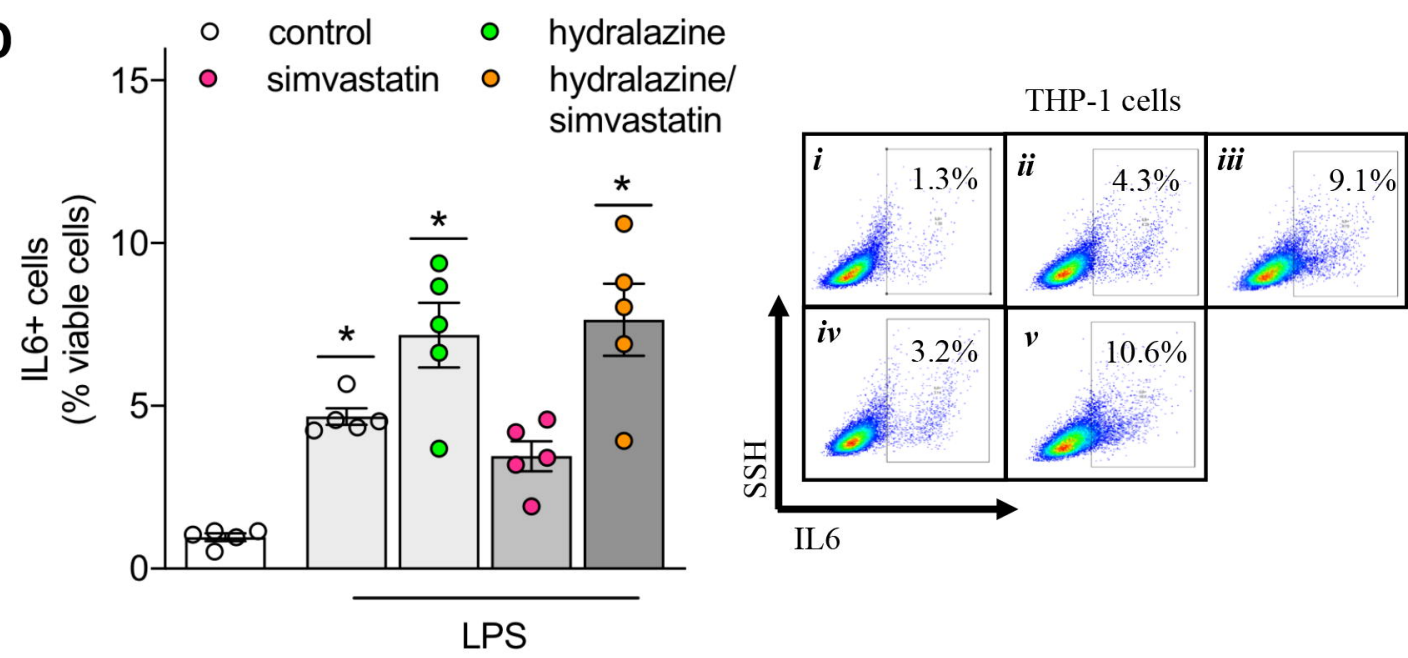

F

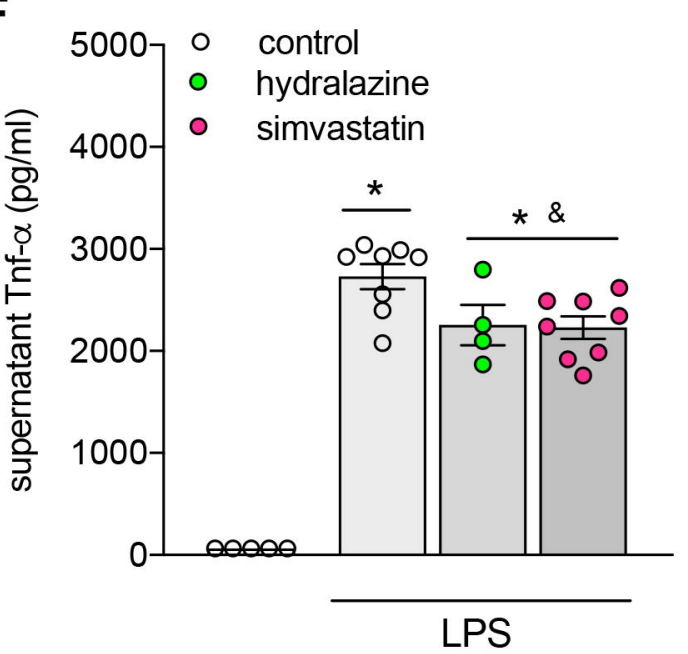

G $8000, \circ$ control

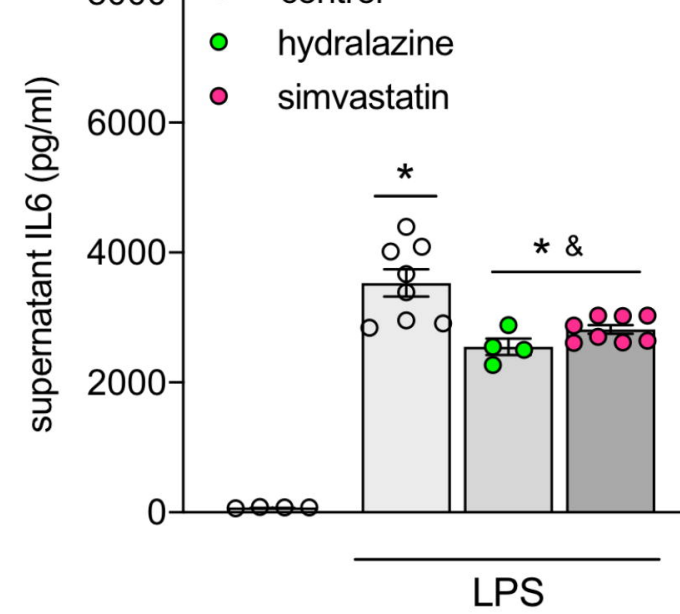

